8. A $\times t$ aus Stahl (Taf. 1, Nr. 8). Kleingefïge: Ferrit, Martensit und Reste von lamellarem Perlit, grobkristallin; g e h är tet.

9. Messer aus Eisen (Taf. 1, Nr. 9). Kleingefüge: Ferrit und Schlackeneinschlüsse, von Rost eingeschlossen; ung e h ä r t e t.

10. M es ser aus Stahl (Taf. 1, Nr. 10). Kleingefüge: a) Klinge: grobkristalliner Martensit; gehä rtet. Mitte der Schneide: Martensit feinkristalliner als an der Spítze. Ende der Schneide: Ferritnetz mit Martensit und Schlackeneinsch]ïssen. - b) Heft: Ferrit und Perlit, Zusammensetzung ungleichmäßig, widmannstättensches Gefüge, grobkristallin; un ge härt et.

11. Lanzenspitze aus Eisen (Taf. 1, Nr. 11). Kleingefüge: Ferrit und Perlit in Zeilenstruktur, Schlacke, im Ferrit Gleitlinien; u ngeh ër tet.

12. S chwert aus Liseu (Taf. 1, Nr. 12). Kleingefüge: teils grob, teils feinkristalliner Ferrit; un g e härt te t.

13. Fe u e s chürer aus Eisen (Taf. 1, Nr. 13). Kleingefüge: Schaufel: Ferrit; ungeh ärtet.

14. Fe u ers ch ür er aus Eisen (Taf. 1, Nr. 14). Kleingefïge: a) Schau. fel: grobkristalliner Ferrit; ungehärtet. - b) Stiel: Ferrit mit geringen Mengen Perlit; unge härtet.

\title{
Die bronzezeitlichen Dosen und Becken aus Mecklenburg
} Von Robert Beltz, Schwerin

$\mathrm{Zu}$ den markantesten Erscheinungen der nordischen Bronzezeit gehören die gewöhnlich als Schmuckdosen und Hängebecken bezeichneten Behälter, welche init Kleingerät und Schmuckgegenständen versehen in den Grabfunden des älteren Abschnittes (Periode III Montelius) sowie Depot- und Votivfunden des jüngeren (Periode IV und V Montelius) Hauptstücke zu bilden pflegen. In dem allmählichen Wechsel ihrer Formengebung und Ornamentik sind sie wie kein zweiter Gegenstand geeignet, den Entwicklungsgang des bronzezeitlichen Stils zu verfolgen; und in der ausgezeichneten Arbeit stellen ihre ausgeprägten Exemplare einen Höhepunkt der bronzezeitlichen Technik dar. So laden sie zu einer zusammenfassenden Untersuchung des gesamten Materials ein, von welcher wir auch mancherlei neue Aufschlüsse über allgemeine Fragen der nordišschen Bronzezeit erwarten dürfen. Eine Vorarbeit dazu soll die folgende Behandlung geben. Sie betrifft einen Befund, welcher der reichste in Deutschland ist. Mit 39 Exemplaren stehen die beiden Mecklenburg an der Spitze der diese Geräte führenden Länder. Und diese Zahl verteilt sich über die ganze Entwicklung. Der eigentümlichen Mittlerstellung. entsprechend, welche Mecklenburg zwischen der im,wesentlichen westlichen 
älteren und der im wesentlichen östlichen jüngeren Bronzezeit einnimmt, besitzen wir in gleicher Weise die älteren und die jüngeren Typen, und zwar in sehr charakteristischer Verteilung. Von den einundzwanzig älteren, den Dosen, gehören nur drei dem Osten des Landes, von den achtzehn jüngeren, den Becken, nur acht dem Westen, und zwar hier auch fast nur densüdlichen, in der jüngeren Bronzezeit bevorzugten Strịchen, während sie auf dem Hauptgebiete der älteren Bronzezeit gänzlich fehlen.

Die folgende Aufzählung folgt einer Typeneinteilung (Abb. 1), welche in wesentlichen die von Montelius, Tidsbestämning S. 74 ist.

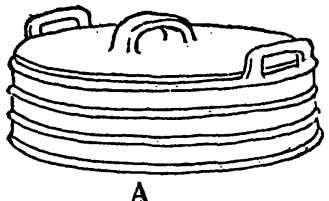

A

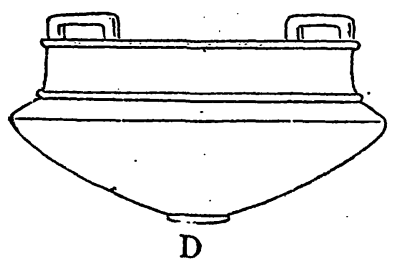

-

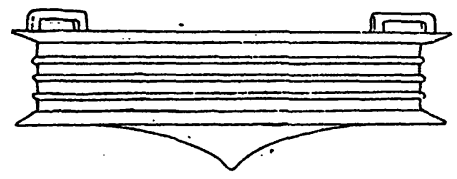

B

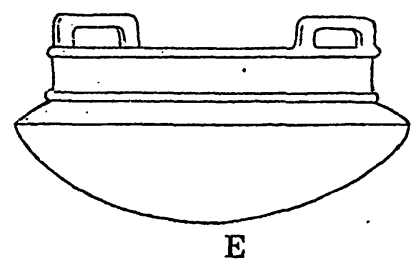

Abb. 1.
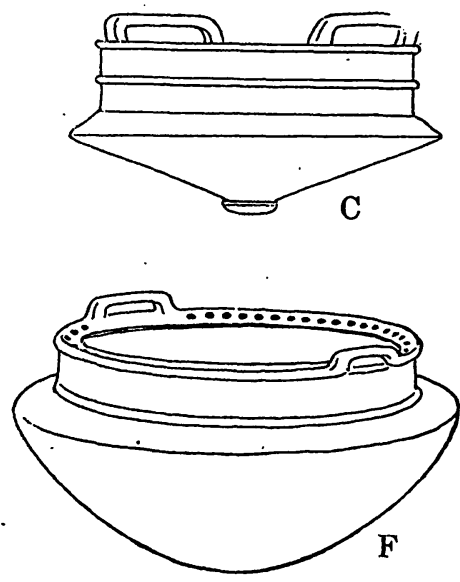

\section{Form A.}

Mo n teli ụs, Tidsbestämning 3,64

Die einfachste und älteste Form sind kleine dosenartige runde Schalen in kräftigèm Bronzeguß mit niedriger gerader Wandung und flachem Boden, meist mit flachem Mittelknopf. Am Wandungsrande zwei aufrechte flache Ösen mit rechteckiger, selten halbrunder Öffnung. Der Verschluß geschieht durch einen flachen Deckel mit einer den Randösen entsprechenden Öse, die Befestigung durch einen durch die drei Ösen gesteckten Holzriegel, von dem mehrfach Reste erhalten sind. Die Ösen auf dem Gefäße selbst sind stets größer als die auf dem Deckel, sollten also noch einer anderen $\mathrm{Be}$ festigung dienen. Durch Beobachtung von Abnutzungspsuren an dem oberen Teile der Öse ist wahrscheinlich gemacht, daß sie am Gürtel getragen wurden, der Boden als Schauseite flach nach außen. Doch mag es noch andere Arten des Tragens gegeben haben. An der Dose von Barnekow unten Nr, 13 sind die beiden Ösen durch einen Faden Golddraht verbunden, womit ein Tragen am Gürtel nicht wohl vereinbar ist. Der Deckel ist stets unverziert. Die Wandung der Dose hat starke Rippen, der Boden trägt reiche Ornamentik. Die Form geht sicher auf Holzschachteln zurück, wie sie ja aus einem älteren Abschnitte der 
Bronzezeit erhalten sind. ${ }^{1}$ ) Die Ornamentik ist eine außerordentlich stabile. Sie geht zurück auf eine Nebeneinanderstellung gerundeter, mit Punktsaum versehener Lappen, die in Zonen gegliedert den Gefäßkörper überziehen Dann werden die Lappen scharfkantiger, trapezoid oder dreieckig und lassen so eine sternförmige Fläche frei, die dann auch als Hauptmuster erscheinen kann. Die Ornamente sind gegossen, der vertiefte Grund wird ausgelegt mit einer schwarzen Harzmasse. ${ }^{2}$ )

Die zeitliche Stellung der kleinen Dosen ist klar, sie sind eine Charakterform der dritten Periode, daher in Mecklenburg, wo diese Periode ja ganz besonders stark vertreten ist, auch häufiger als in den Nachbarländern.

Sie kommen nur in Frauengräbern vor und sind sicher als Schmuckbehälter aufzufassen. Ihr Inhalt ist Kleingerät und besonders goldene Ringe, die ja auch Zahlungsmittel waren. Es ist ein niedlicher kulturgeschichtlicher Zug, daß in der älteren Bronzezeit die Frau das Portemonnaie hütet.

Am Schluß der Periode tritt eine doppelte Ändernng nach verschiedenen Richtungen ein: die Dosen werden einfacher gebildet, die Rippen verschwinden, die stärkere plastische Heraushebung der Lappen hört auf, Alles wird glatter, ein einfaches Sternmuster überwiegt (Beispiel Spornitz unten Nr.11). Oder im Gegenteil, die Ornamentik wird freier und üppiger, die Lappen werden verbunden ,und bilden ein bewegtes Band usw. (Beispiel unten Nr. 8), ein Ausdruck jener stilistischen Richtung am Schluß der Periode, von der sich dann der reichere Stil der jüngeren Bronzezeit herausgebildet hat.

Mit denSchmuckdosen gehören gewisse kegelförmige Sch muckpla t ten (Buckel, Hütchen, tutuli, Stachelknöpfe) zusammen, dì häufig mit ihnen ge-funden werden und nach ihrem ganz allgemeinen Auftreten in Frauengräbern offenbar zur weiblichen Schmuckgarnitur gehören. Die durchgehenden Züge sind eine geringere oder stärkere Wölbung, eine Spitze únd eine Befestigung zum Anbringen am Gürtel oder sonst am Gewande. Diese besteht in der älteren Zeit aus einem einfachen Stege. Die Ableitung. aus den prachtvollen Schmuckplatten der älteren Bronzezeit (Periode IL). ist deutlich. Unter den hiesigen Exemplaren tritt sie nur an dem von Peckatel (Abb. 5) hervor. Neu ist der Abschluß der Spitze durch eine: Scheibe oder eincn flachen Kegel. Häufiger ist die einfache Form Abb. 3 . (von Plate). Später, besonders am Ende der, Periode (im wesentlichen III $\mathrm{b}=\mathrm{S}$. M üller $\dot{\mathrm{V} I}$ ) ändert sich die Befestigungsweise und damit.

1) Dazu und zu dem Folgenden S: M üll er, Nordische Altertumskunde I S. 351 f.. N e e r g a a rd, Nordiske Fortidsminder I, $3 \mathrm{~S} .85 \mathrm{f}$.

2) Die Rippen gehen natürlich auf die Holzreifen zurück. Wenn man auch für das: Bodenornament einen technischen Ursprung suchen will, könnte man an die Lappen einerLederumhüllung denken, mit welcher die Holzschalen umkleidet wurden; dann erklären sich auch die beliebten Punkt- und Querstrichsäume als Nähtẹ, die Harzeinlage als ursprünglicheDichtungsmasse. Aber nötig ist das nicht. Lappen wiẹ Harzeinlage kommen in andererArt schon in einer älteren Stufe der Bronzezeit vor. 
die Form, indem die Befestigung durch eine kleine Scheibe, die am Kegel durch eine kleine. Stange verbunden ist, hergestellt wird (VAM 33,109; mit dosenartigem Gefäß Vorbeck unten Nr..17.).

\section{Dabel bei Sternberg $I^{3}$ )}

Drei Rippen an der äußersten Wandung. Boden: gestricheltes Doppelband, zwei Zonen Lappen. Mittelknopf mit vier kleinen Lappen. Auf dem Deckel Eindrücke des Riegels (wohl aus Holz).

Höhe 2,3 cm, Durchmesser (innere Weite) oben $8 \mathrm{~cm}$, unten $9 \mathrm{~cm}$. Abb. 2.

Ausgegraben 1856 (Mecklenb. Jahrb. 22, S. 279). Auf dem Grunde eines Kegelgrabes von etwa $3,75 \mathrm{~m}$. Höhe, $23 \mathrm{~m}$ Durchm. Doppelbegräbnis, der Mann unverbrannt beigesetzt, wohl auch die Frau. ${ }^{4}$ ) $\mathrm{Zu}$ dem Frauengrabe

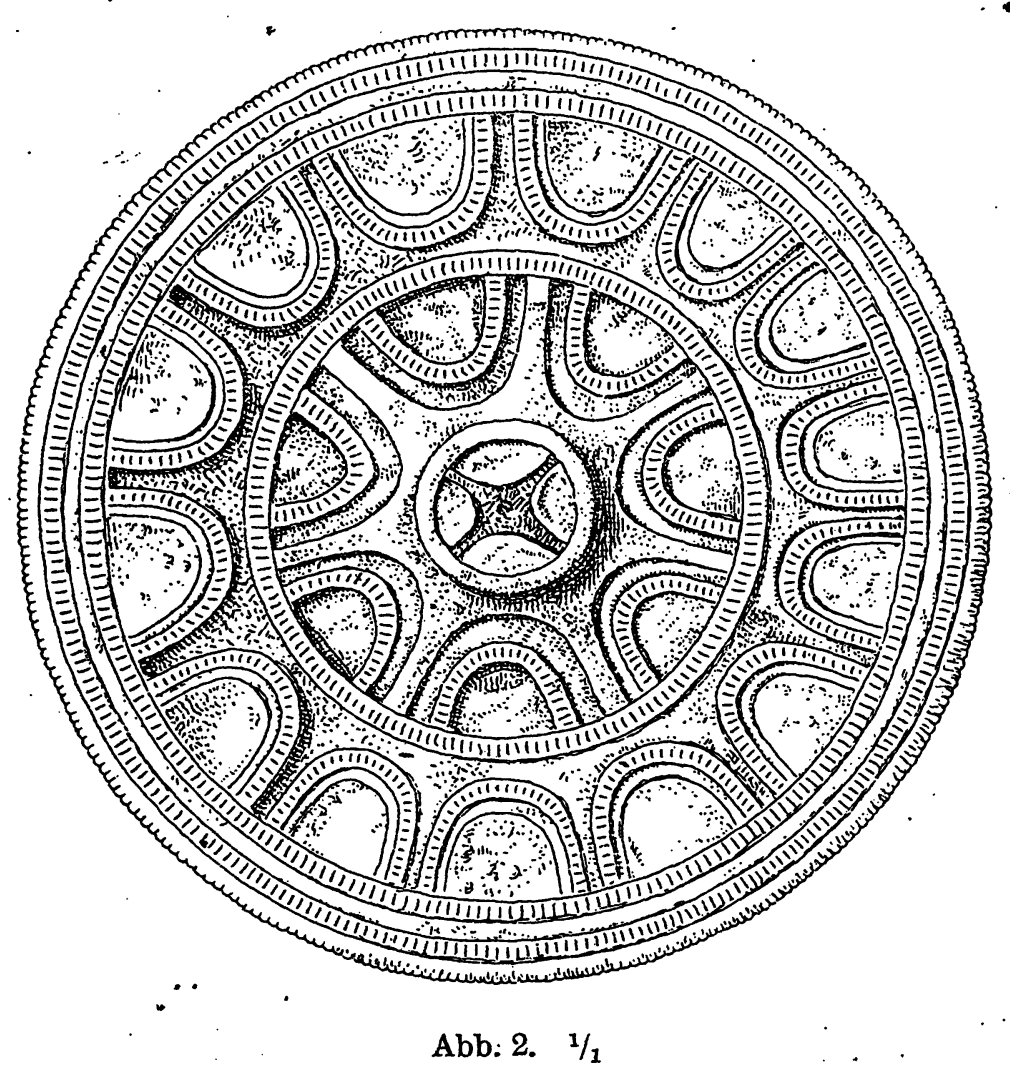

gehörend. Am Kopfende die Schmuckdose, in der Mitte: 2 Messer (= VAM 26, 38,41 ), Meissel (= VAM 27, 44), br. Fingerring (= VAM 33, 94), Gürtelknopf (= VAM 33, 108), Schmuckplatte (Tutulus), niedriger als Abb. 3, sonst gleich, H. 2, Dm. $3,5 \mathrm{~cm}$.

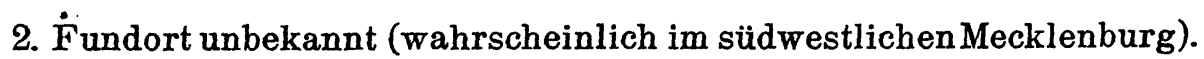
Ähnlich dem Stück von Dabel. Drei Rippen. Öse halbrund. Boden: gestricheltes Doppelband, eine Zone Lappen, auf dem Mittelknopf vier kleine Lappen. Höhe 3, Dm. oben 7, unten $8 \mathrm{~cm}$. Alter Bestand (vor 1822); nach der Patina Grabfund.

3) Soweit nichts anderes bemerkt, befinden sich die besprochenen Gegenstünde im Museum zu Schwerin.

4) Der Bericht nimmt Verbrennung der Frau an, anscheinend weil keine Gebeine erhalten sind, doch spricht das eher für Beerdigung als für Brand. 
3. Sandkrug bei Lübz V.

Drei Rippen aus gestrichelten Doppelbändern, Saum aus Doppellinien. Boden: $Z$ wei Zonen Lappen, die Vertiefungen weniger tief, wodurch die ganze Fläche glatter wird, alle Verzierungen besonders fein.

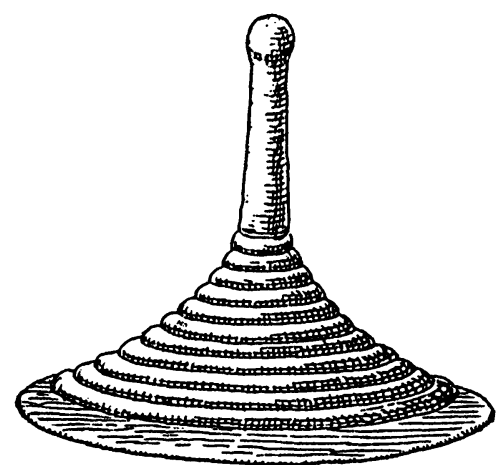

Abb. 3. $1 / 1$

Höhe $2, \mathrm{Dm}$. oben 6 , unten $6 \mathrm{~cm}$ (also wesentlich kleiner als die anderen). Ausgegraben 1854 (Jahrb. 19 S. 310). Niedriges Kegelgrab. Außer der Dose ein Armring (= VAN 30, 81).

4. Vogelsang bei Güstrow.

Nur einige Bruchstücke. Ǎhnlich dem ron Sandkrug, aber größer. Boden: Zwei Zonen Lappen, die der äußeren höher und schmaler, die der inneren halbrund; dazwischen gestrichelte Linienbänder.

In einem 1869 dưrch Beackerung zerstörten Grabe. Dabei ein Halsring = VHM 30, 76.

\section{Plate bei Schwerin.}

Vier Rippen. Boden: 2 Zonen Lappen, kleiner als bei Dabel usw. und an den Enden eckig.

Höhe 3, Dm. oben 10, unten 10,3 cm. Flacher Deckel wie gewöhnlich, in der Öse Holzreste.

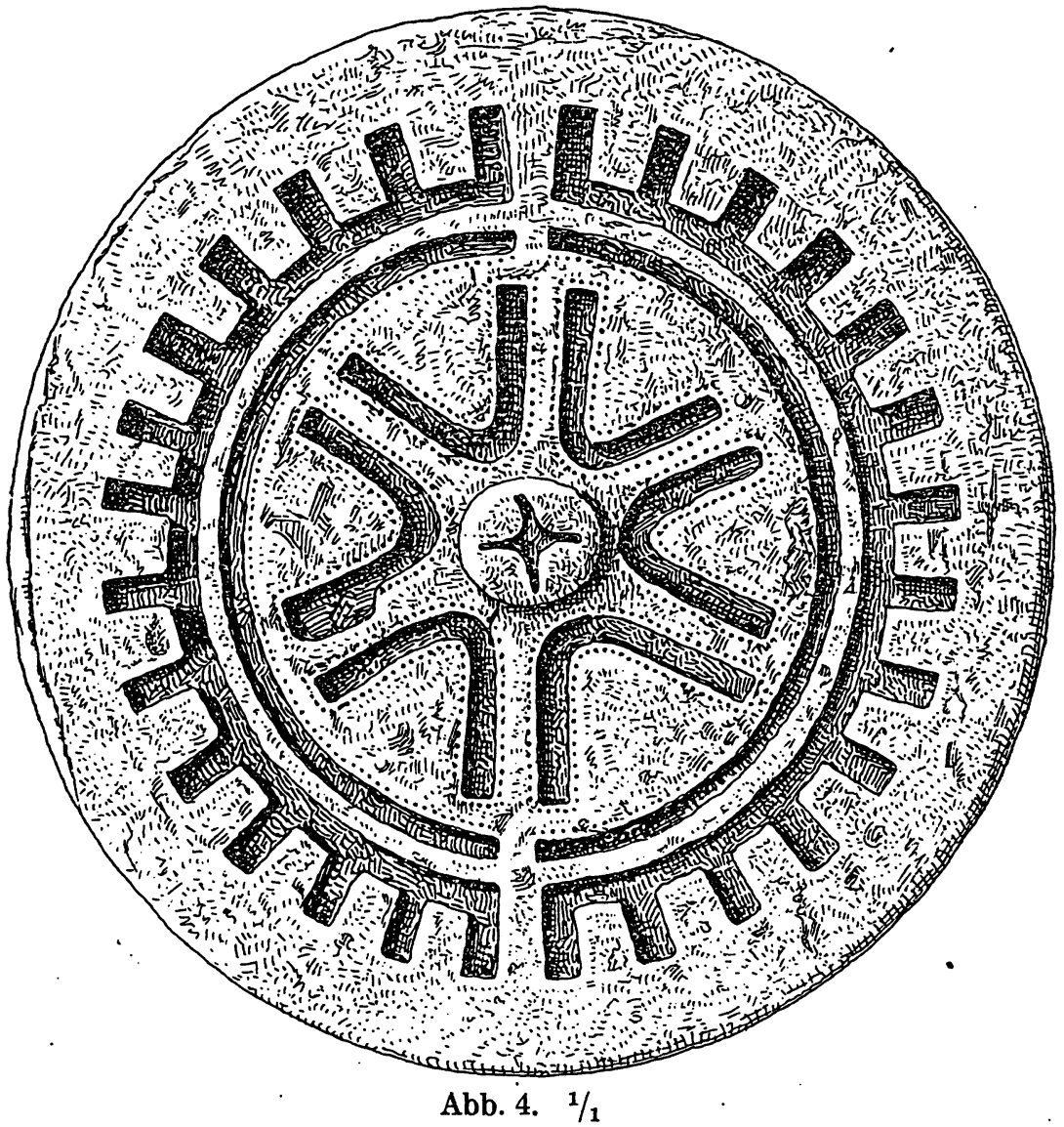

Gefunden 1903 in einem niedergeackerten Kegelgrabe von etwa $20 \mathrm{~m} \mathrm{Dm}$., dem "Radelsberge", rechts von dem Wege nach Suckow, östlich vom Dorfe, etwa $750 \mathrm{~m}$ von der Kirche. Büdner $\mathrm{S} \mathrm{ch} \mathrm{w} \mathrm{a} \mathrm{n} \mathrm{b} \mathrm{e} \mathrm{c} \mathrm{k} \mathrm{stieß} \mathrm{beim} \mathrm{Steinebrechen}$ auf Gebeinereste in westöstlicher Lagerung. Nahe dem Kopfe rechts lag die Schmuckdose, angeblich leer; nahe dabei eine Schmuckplatte (Abb. 3) der Form 
VAM 33, 104; Höhe 3,5, Dm. 4,2 cm. Am Halse ein gewundener Ring ähnlich VAM 31, 78, die Enden abgebrochen, anscheinend spitz zugehend; in der Gegend der linken Hand ein spiraliger Goldring, Form VAM 33, 98 von $4 \frac{3}{4}$ Windungen, $5 \mathrm{~g}$ schwer. In der ausgeworfenen Erde, also unbestimmter Lagerung, ein zweiter Goldring, sehr ähnlich dem ersten, von 5 Windungen, $5 \mathrm{~g}$ schwer, und der obere Teil einer langen Nadel mit starkem halbkugeligem Kopfe, Form VAM 28, 56. - In demselben Hügel ist 1905 ein zweites Grab zerstört, aus dem der obere Teil einer bronzenen Nadel mit rundem Kopfe mit Querriefelungen und die Reste einer tönernen Henkelschale geborgen sind.

Das Grab enthält echtes M III-Inventar und ähnelt damit den benachbarten berühmten Gräbern von Peckatel.

6. Peckatel bei Schwerin II.

Vier Rippen, eingefaßt von Punktreihen. Öse halbrund. Boden: Zwei Zonen Lappen, die der äußeren trapezoid, die der inneren dreieckig (Vorbereitung des Sternmusters). Die Vertiefungen sind so tief, daß der Grund sehr dünn wird und an einigen Stellen ganz fehlt.

Höhe 3,5, Dm. oben 9,2, unten $10 \mathrm{~cm}$. Abb. 4 .

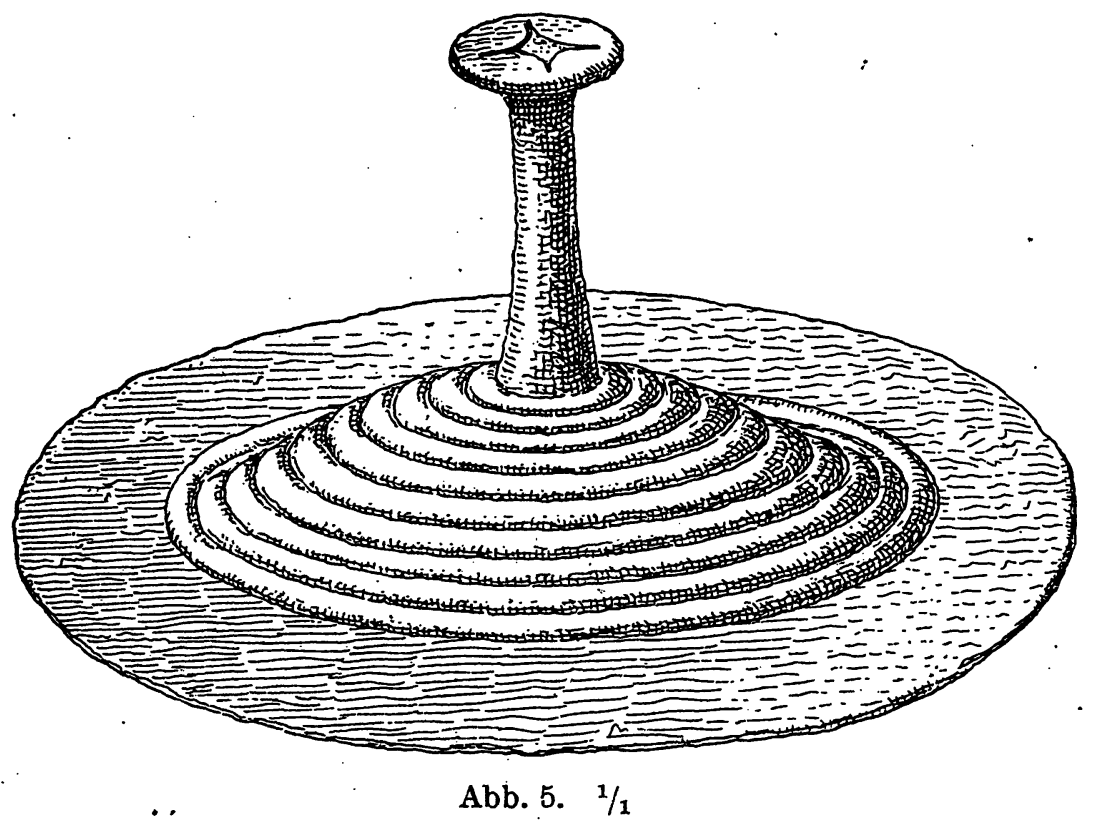

1845 in dem Kegelgrabe "Rammelsberg" durch Raubbau geborgen, der Hügel dann von $L$ i s ch untersucht (Jahrb. 11 S. 366): neben zerbrannten Gebeinen und vom Feuer beschädigt ein Paar Handbergen (= VAM 32, 87), zwei gewundene Halsringe (=VAM 31,78$)$, fünf Handringe (=VAM 31,83$)$, die Schmuckdose, eine Schmuckplatte ungewöhnlicher Form (das Stück ist im Feuer gewesen und stark entstellt, aber in allem wesentlichen erkennbar), breiter, flacher und größer als gewöhnlich (wie oben bei Plate), mit starker Aufsatzstange, die in einer runden Scheibe mit Sternverzierung endet (Abb. 5). Dm. ung. 7,5, Höhe ung. 5,5, Dm. der Kopfscheibe 1,3 cm, 5 Bernsteinperlen (=V.AM 34,118). - Typisches Frauengrab der dritten Periode.

7. Feldberg (Meckl.-Strelitz).

Wandung glatt, unten 5 umlaufende Linien. Boden: Die Zonen durch ein breites Band mit umlaufenden Linien getrennt; zwei Zonen: Kleine Lappe mit Punktsaum.

Höhe 2,5, Dm. gleichmäßig $7 \mathrm{~cm}$. Abb. Zeitschr. f. Ethn. 1880, Taf. XV, 1. Märkisches Museum, Berlin.

Auf der Halbinsel (früheren Insel) Mönchswerder (a. a. O. Verh. S. 308). Darin fünf goldene Spiralringe. 
8. Fundort unbekannt (wahrscheinlich im südwestlichen Mecklenburg).

Vicr Rippen. Boden etwas alsweichend: eine Zone Lappen mit innerem Punktsaum, in denen Würfelaugenkreise, an Stelle der zweiten Halbkreisbögen, die durch Bogenlinien verbunden sind, darunter runde Vertiefungen (sechsteiliges Muster). Auf dem Mittelknopf einfacher Stern (Kreuz). Starke Verticfungen. Der jüngore Charakter äußert sich nicht nur in den Kreuz- und Bogenverzierungen, sondern auch darin, daß auf dem Boden innen eine runde Tertiefung, durch die er etwas hinuntergedrückt wird, also nicht mehr ganz flach ist.

Höhe 2,5, Dm. oben 7, unten 7,7 cm. Abb. ${ }^{r} 6$. Friderico-Francisceum XII, 4. Alter Bestand (vor 1822); nach der Patina Grabfund.

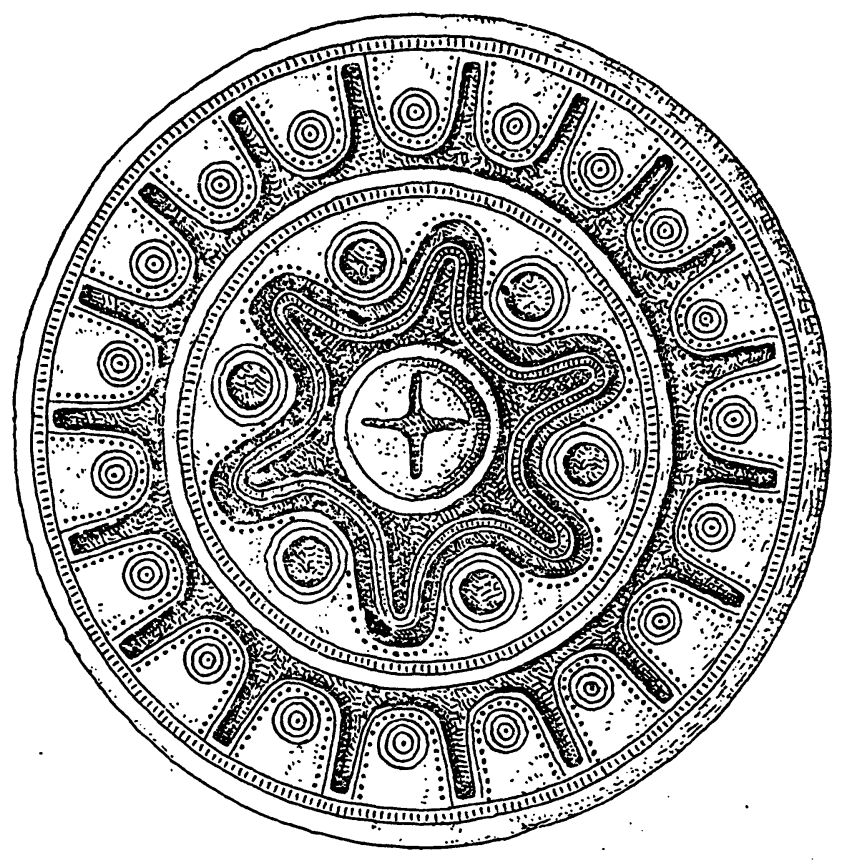

Abb. 6. $1 / 1$

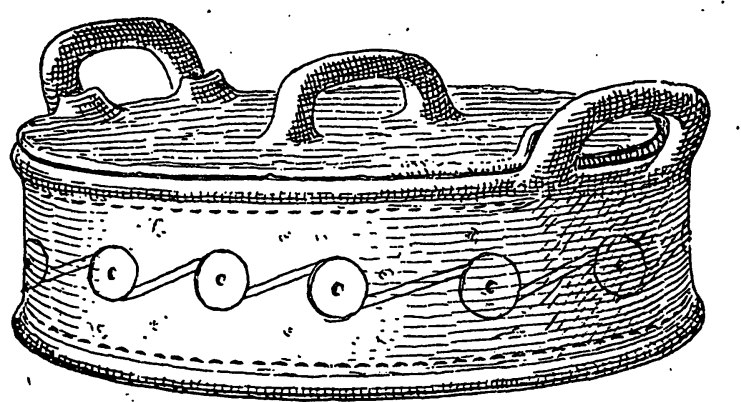

Abb. 8. $1 / 1$

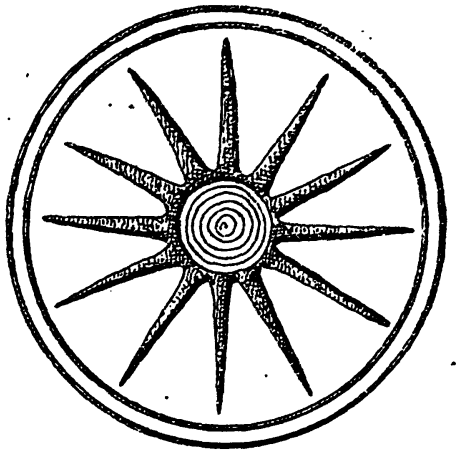

Abb. 7. $1 / 1$

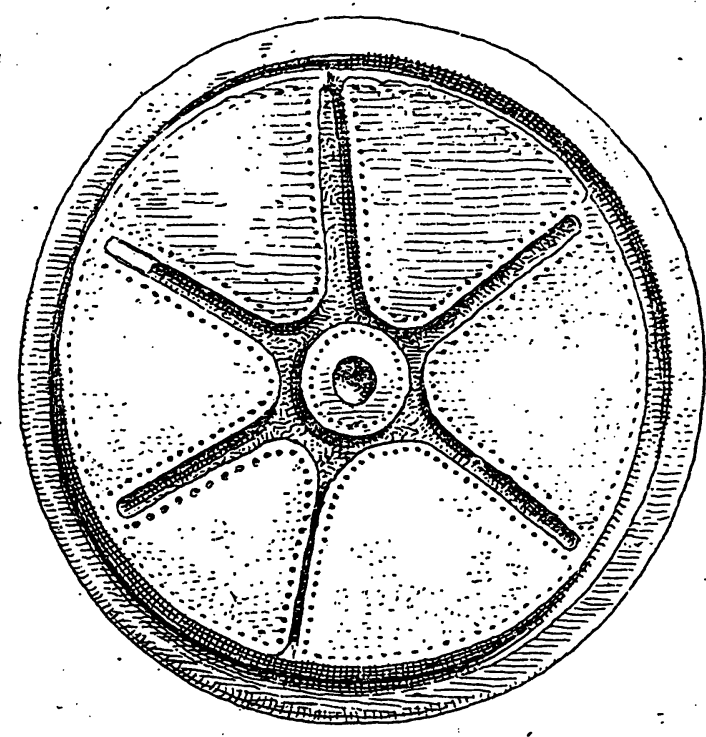

Abb. 9. $1 / 1$

\section{Ruchow bei Sternberg.}

Keine Rippen. Öse halbrund. Boden: Drei Bandstreifen, die beiden äußeren gestrichelt. Die Lappen zugespitzt, so daß ein Sternmuster entsteht (12 teilig). Mittelknopf mit konzentrischen Kreisen.

Höhe $2, \mathrm{Dm}$. oben 8,8 , unten $9 \mathrm{~cm}$. Abb. 7 .

Ausgegraben 1820/1821 (Jahrb. 5 B S. 30). Kegelgrab „Königsberg“" 6 m Höhe, $19 \mathrm{~m}$ Dm.

Neben einem beerdigten Skelett (Männergrab) Leichenbrand (Frauengrab) mit weiteren Beigaben: Messer (= VAM 26, 38), große Nadel (= VAM 27, 53), 
2 Halsringe (=VAM 31, 78), Tutulus jüngerer Form, Doppelknopf (=VAM 33, 109), 2 Paar Armringe (= VAM 31, 85), zwei Handbergen (= VAM 32, 87), zwei goldene Spiralringe (= VAM 33, 98), Tasse aus Bronzeblech (= VAM $34,115)$, Tongefäß (zerbrochen). Die Gegenstände lagen zusammengedrängt auf einem Raum von etwa 1/2 Quadratmeter.

Die Ausstattung entspricht der der Gräber von Dabel und Peckatel.

10. Wozeten bei Laage.

Zwei formlose, im einzelncn nicht erkennbare Reste. Im Winter 1901/02 war ein niedriger Erdhügnl entfernt und bei dieser Gelegen ein br. Schwert (Form VAM 2y, 14) gefunden. Die Untersuchung ergab, daß dieses einen auf einem Steindamm liegenden, nach W. blickenden Bestatteten gehörte, den auch zwei steinerne Pfeilspitzen mitgëgeben waren. Auf $\cdot$ der andern (nördlichen) Seite des Hügels lagen im Erdăuswurf Reste mit Halsringel, etwa in der Form VAM 30, 66 und die beiden Bruchstücke der Schmuckschale, die also hier wiederum ähnlich wie in Dabel und Ruchow einer weiblichen neben einer männlichen liegenden Bestattung angehört hat.

11. Spornitz bei Neustadt.

Die Ösen etwas nach außen biegend. Keine Rippen. Auf der Wandung Würfelaugen, durch Doppellinien tangential yerbunden („falsche Spiralen“). Boden: Sechs glatte Lappen, mit innerem Punktsaum. die ein Sternmuster freilassen. Der Mittelknopf leicht erhaben.

Höhe 2, Dm. oben 6, unten 6,5 cm. Abb. 8 u. 9. Friderico-Francisceum Taf. XII, 3.

Gefunden vor 1804 (Frid. Franc. S. 49). Keiñ Fundbericht. Es liegen dảbei eine Anzahl offenbar zu einander gehörender kleiner Bronzegegenstände meist der fünften Periode, einige vielleicht noch der vierten. In späterer Zeit sind bei Spornitz noch ein Grab der dritten und niedrige Hügelgräber (wohl der vierten Periode) bekannt geworden (Nachweise s. VAM). Ob das Gefäß zu einem dieser zwei Funde gehört (die erste Gruppe ist ausgeschlossen), ist aus dem Befunde nicht zu bestinamen.

Jedenfalls stellt es eine starke Vereinfachung der alten Form dar und dürfte wie die ganz gleich verzierten Halskragen in Schleswig-Holstein und wohl auch die gleich geformten Dosen dort in die Schlußperiode von Periode III fallen, wenn es nicht noch jünger ist. ${ }^{\text {) }}$

\section{Form B.}

M o n te lius, Tidsbestämning 4, 91, N e e r g a a r d, Nordiske Fortidsminder I, S. 89; T. XVIII.

Das Neue in - der Formengebung ist die Vertiefung des Bodens und dessen Ausziehung zu einer Spitze, also derselbe stilistische Zug, der Ende der Periode III herrschend·wird. Zugleich werden die Profile schärfer, der Halsrand und der Boden biegen scharfkantig aus. Auch kommen die Stücke in das Wachsen und nehmen größere Ausmessungen an.

Die Ornamentik bekommt einen anderen Charakter. Die Motive werden rundlicher und bewegter, die Lappen werden gern an der Basis verbunden und gebogen, Halbkreise und besonders kleine Kreise (Würfelaugen a. a.) treten auf. Es ist der Stil der Scblußphase ${ }^{6}$ ) der dritten Periode (S. M ülle rs Periode VI). Noch bleibt der flache Deckel, die

5) Vgl. z. B. den Fund von Schalkholz Splieth 268 mit soinem jungen Inventar Falsche Spiralen s. unten auch an den Dosen von Barnekow und Parchim; sie kommen noch in Periode IV vor; vgl. das hannoversche Hängebecken Typ D in Lindenschmit A. II, 9 Taf. 1, 5 und den Tutulus S. Müller, Ord́ning 370.

e) Mémoires 1908/13 S. 134. Der SchluBknopf des Bodens bei den mecklenburgischen Stücken entspricht oft genau dem dort abgebildeten Knopf. 
Harzeinlage und die Ausführung der Ornamente in Guß, doch treten schon punzierte Ornamente daneben.

Die Mehrzahl der Funde dieser Fornn wird nicht mehr in Gräbern, sondern in Mooren und als sonstige Depots gefunden. Das ist bezeichnend für ihre Zeit, die ja sicher nach den großen bronzezeitlichen Grabbauten liegt. Auch die Beifunde zeigen (s. u.) einen wesentlich anderen $\mathrm{Cba}$ rakter und neigen zur Periode IV hin. Wenn ich diese Dosen lieber an den Schluß.von III setzen möchte (so auch S. M üller und Ne e r ga a rd) als an das Anfangstadium von IV (so Montelius), so ist dafür maßgebend, daß sie sich noch auf dem Wege der Stilentwicklung von III bewegen. Vielleicht kann man auch noch zwischen den kleineren, von denen zwei sicher III b sind und den größeren mit stärkerer Zuspitzung (Güstrow usw.) scheiden und diese in IV setzen. Nicht unerwähnt darf aber bleiben, daß das Exemplar von Zepelin die Olshausenschen „Verstärkungsrippen" hat, eine Technik, die sonst erst an Stücken der vierten Periode beobachtbar ist. ${ }^{7}$ )

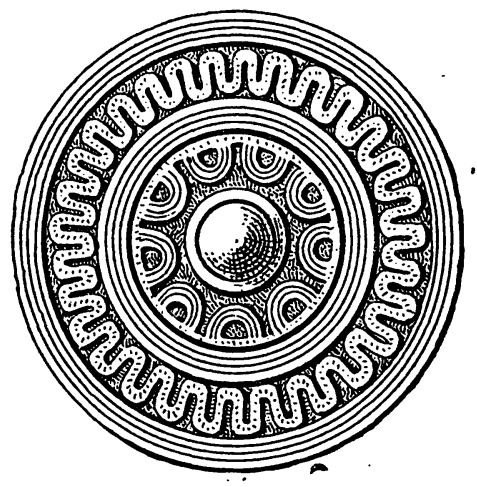

Abb. 10. $1 / 2$

12. Zepelin bei Bützow.

Nur der Boden erhalten. Zonen: 1. Saumband aus sechs Strichlinien. 2. Zu einem Wellenbande zusammengestellte Lappen mit Vertiefungen. 3. Band aus sechs. Strichlinien. 4. Neun stehende Bögen (aufgehöht).

Dm. 10,5 cm. Abb. 10. (näch VAM S. 167, 19) Friderico-Francisceum XII,5. Gefunden 1781 ,auf dem Felde“.. Ohne Patina, also wohl Moorfund.

13. Barnekow bei Wismar.

Halsrand und Bodenrand gestrichelt; in der Mitte der Wandung drei gestrichelte Bänder; in der unteren freien Fläche Würfelaugen durch Doppellinien tangential verbunden, ähnlich wie an dem Exemplar von Spornitz. Boden: 1. Breites Saumband aus zarten Linien und Linienbändern, diese zum Teil gestrichelt oder mit kerbschnittartiger Dreiecksverzierung; 2. Lappen; 3. Band aus Strichlinien; 4. elf aufgehöhte Kreise. Mittelknopf mit Stern.

Höhe 2,2, Dm. oben 9,2, unten 10,3 cm. Abb. 11 .

Gefunden 1880 in einem Torfmoor (Jahrb. 46 S. 300). Durch die Ösen ist ein Goldfaden gezogen, dessen Enden verknotet sind. In der Dose lagen zwei goldene Spiralringe und ein bronzener Pfriemen, abg. VAM 27, 47.

Weitere Funde: 1. zwei größere Tüllenäxte, abg. VAM. 22, 9: 2. zwei starke „Beinringe“ mit rhombischem Querschnitt, Zusammenschnürung und dann Verbreiterung der Enden, einfachem Punktsaummuster; 3. zwei schwache Handringe mit kleinen Stollen, einfachem Schrägstrichsaum und Querstrichen, ähnlich VAM 40,66; 4. drei gewundene Halsringe mit Hakenschluß = VAM 40,59, aber ohne Wechsel der Windung; 5. Armring aus Spiraldraht von flach gewölbter schwachkantiger Oberfläche, die Enden breitgehämmert; 6. zwei gleiche - mit scharfkantiger Oberfläche = VAM 32, 92 .

Zur Zeitstellung des Fundes. Es wird zurzeit kaum möglich sein, zu bestimmen, ob wir ihn noch in Periode III (so VAM S. 232) setzen dürfen oder schon der nächsten zuschreiben müssen. Die Grenzen dieser schwankenden Perioden, in denen der alte Stil verloren ist, ein neuer sich aber erst langsam herausbildet, sind ja noch durchaus flüssig. Jedenfalls ist er jünger als die Masse der Gräberfunde, von denen er sich durchaus unter-

?) Z. f. E. 1885 S. [410]. Ne erg a.ard a. a. O. S. 94. 
scheidet, und wirkt fremdartig. Die Tüllenaxtform kommt nur in dem ebenfalls ganz jungen Grabe von Vorberk der Periode III b vor, ${ }^{8}$ ) der Pfriemen ähnelt jungbronzezeitlicher Formengebung, ${ }^{9}$ ) neu sind Arm- und Beinringe mit verbreiterten Enden und mit Punktverzierung, und der scharfkantige Armring, der auch, allerdings in noch stärkerer Ausprägung in die fünfte Periode (Brook usw.) reicht. Will man Barnekow schon zu IV rechnen, so zieht es die Funde von Meteln, Mecklenburg, Pamgow und Gr. Schwaß (VAM S. 232) nach sich.

14. Gr. Schwaß bei Rostock. ${ }^{10}$ )

Prachtstück, wesentlich größer als die bisher besprochenen. Der ZBoden und der Rand laden scharfkantig aus. Drei stark hervortretende Rippen mit Querstrichelung.

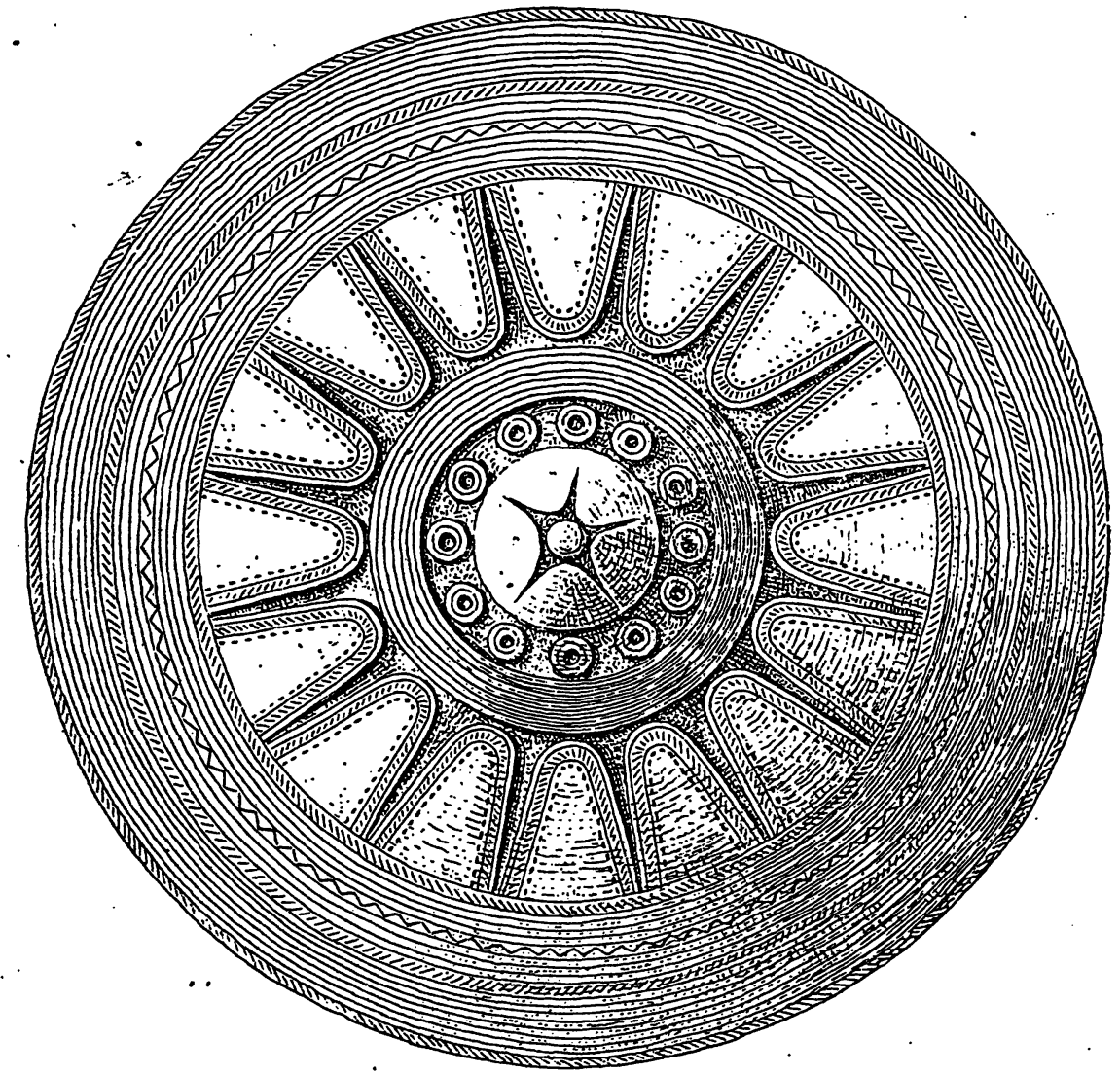

Abb. 11. $1 / 1$

Boden. Zonen: 1. Stehende Halbkreise aus je vier punzierten Linien mit Punktsaum. 2. Hohe schmale Lappen mit gestricheltem Bandsaum und den Rändern parallele Punktlinien. 3. Band aus sechs Strichlinien. 4. Trapezoide Lappen mit Tannennadelornament $5 .=3$. Mittelstück stehende Halbbögen $=1$. Achtteiliger Stern aus hohen Lappen mit Tannennadelornament, deren Achsen vertieft sind und wieder einen Stern bilden. - Mittelknopf mit Saumlinien.

Höhe 6, Höhe der Wandung 3,5, Dm. oben innen 18,5, außen 20,3, unten $21 \mathrm{~cm}$. Abb. 12, 13, 14.

8) Der allgemeine Typ ist allerdings älter; s. S. Müller, Mem. 1908/13 Abb. 22, reicht aber bis MF (Broik).

\%) S. Müller, Ordnong 200.

10) Früher wurde irrtümlich Kritzemow als Fundort bezeichnet. 
Gefunden 1871 in einem Torfmorr (Jabrb. $37 \mathrm{Si}$ 199). Dabei zwei Handringe. diinnwandig, mit starker innerer Wölbung und tiefen Querfurchen, al)g. VAM 31. 82 (vgl. S. Müller, Ordning 112), frühestens einem ganz späten Teile der Periode III gehörend.

\section{Gegend von Güstrow.}

Ahnlich den Becken von Gr. Schwaß, aber mit höherem Halse und stärkerer Zusipitzung des Bodens. Die Ösen mit Schrägstrichstreifen. Hals ausgebogen und gestrichell, am Bodenansatz ein zweiter ganz gleicher Streifen. T) rei Rippen mit Schrïgstrichen und Dreiecksaum.

Boden: 'l'annenwedlelsaum, die Zonen geteilt durch ein ähnliches Band oder schrïg gestrichelte Bünder. Zonen: 1. Stehende Bögen aus je drei punzierten Linien. 2. Hohe schmale Lappen mit Punktsaum innen und axialer l'unktlinie, die $\mathrm{Z}$ wischenräume mit Harzfüllung $3=1,4=2$. Im Mittelstück sechs stehende Halbbögen aus je vier Linien, die $\mathrm{Zwischenräume} \mathrm{mit}$ Haryfiillung. Der spitze Knopf mit gestrichelten Linien eingefaßt.

Höhe der Wandung 4, Dm. oben $17,3 \mathrm{~cm}$, unten $18.5 \mathrm{~cm}$. Höhe mit Öse 8,5; ohne Öse $7 \mathrm{~cm}$.

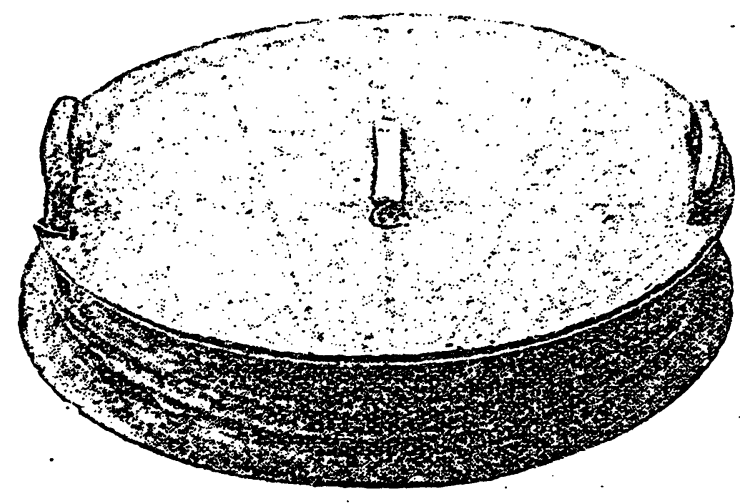

Abb. 12. $1 / 6$.

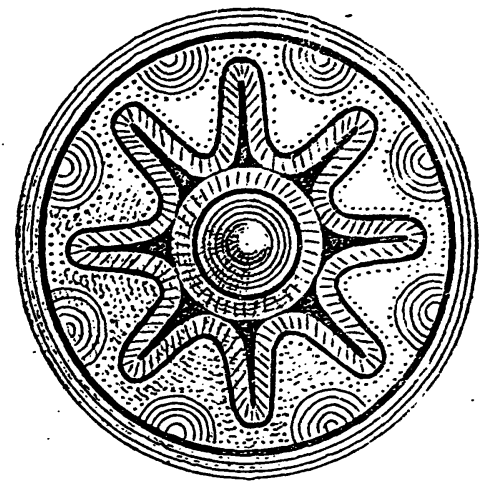

Abb. 14

Museum Breslau. Abb. Baltische Studien XII, 30, Taf. 2. Korrespondenzblatt der deutschen anthr. Ges. 1906 S. 128, A.bb.-10.

Gefunden 1803, näheres nicht" bekannt.

Beifunde: große Fibel mit Kreuzbalkennadel (wie Zeitschr. f. Ethn. 1913 S. 671, A.bb. 8), 11) drei Handgelenkringe mit sich verjüngenden Enden und Augenverzierungen (Korrbl. a. a. 0. Abb. 9), unvollständiger Armring ähnl. VAM 30,81 .

\section{Goldenbow bei Crivitz.}

Bruchstücke. Drei Rippen. Boden: Saumband aus 5 Linien. Lappen, die ein, anscheinend sechsteiliges, Sternmuster freilassen. Keine hochstehenden Ösen, sondern eine seitliche (horizontal). ${ }^{12}$ ) Vielleicht keine Dose, sondern ein Deckel oder Beschlagstück.

Höhe 1,5, Dm. unten etwa $6 \mathrm{~cm}$.

Gefunden 1858 beim Steinbrechen in einem Hügelgrabe (Jahrb. 26.S. 135). Damit zusammen eingeliefert:Schwert=S.Müll er, Mém. 1908/13 S. 135, Abb. 122; Fibel abg. VAM 29,70; Bruchstück. einer Fibel = VAM 29. 73; Nadel abg. VAM 28, 61; Bruchstück eines Messers (?); Bruchstücke eines rundstabigen und eines flachen Armrings; Teile eines Stuhlbeschlages, ähnl. Kn orr, Mitt. d. anthr. Vereins Schleswig-Holstein XIV,. 1901 S. 5, aber kleiner: Abschlußknopf mit genau derselben Verzierung wie die "Schmuckdose" und auch ent-

11) Die Zugehörigkeit der Fibel zu dem Funde ist nicht wahrscheinlich, da sie ganz andere Patina besitzt. (Nach gefälliger Mitteilung des Herrn Dr. Jahn in Breslau).

12) Seitliche Osen auch an einem dünischen Exemplar der Form A, s. S. Müller, Ordning I, Text zu 124. 
sprechender Form, Endbeschlag der Stäbe. Man könnte annehmen. daß auch unser Stück zu dem Stuhlbeschlage gehört, aber in Vorbeck (s. unten) ist ein völlig entsprechendes unter Umständen, die für seine Verwendung als Dose sprechen, gefunden.

Das Grab ist von besonderem Interesse, denn es vertritt in reinster Form die bisher nur wenig beachtete Schlußstufe der drilten Periode, die S. Müller als besondere, sechste Periode der älteren Bronzezeit ausgesondert hat (s. Mém. a. a. O.).

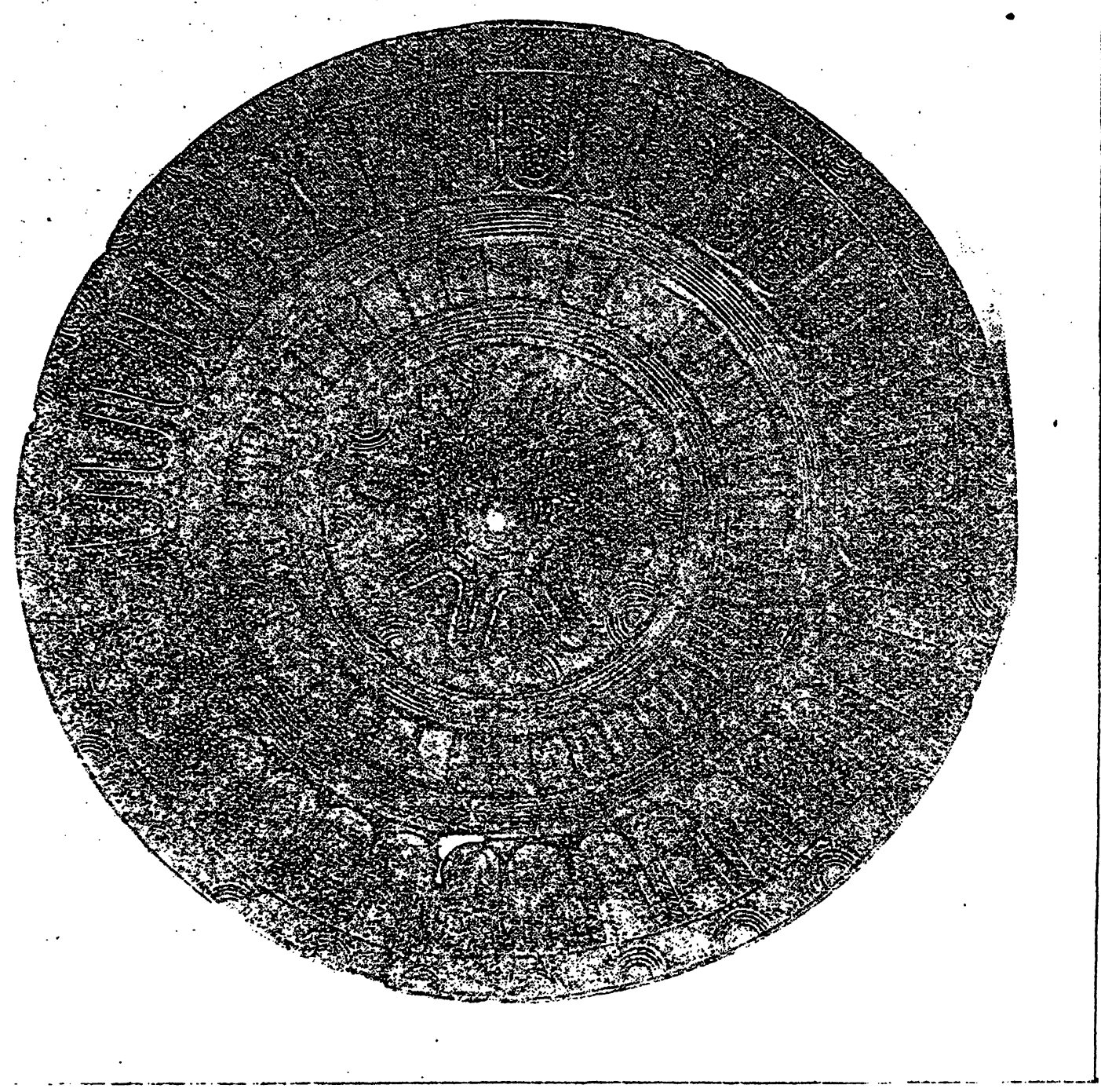

Abb. 13. $2 / 3$

17. Vorbeck bei Crivitz I.

Ähnlich dem Stüick ron Goldenbow. Drei Rippen. Seitliche Öse. Boden: Siebenteiliger Stern, die andere Fläche glatt. Mittelknopf mit fünfteiligem Stern.

Höhe 2, Höhe der Wandung 0,9, Dm. oben 5,3, unten 5,6 cm. Abb. 15. Ausgegraben 1864 (Jahrb. 30 S. 145). Niedriges weites Hügelgrals (7,5 m D. M.). In einer Bodenmulde zerbrannte Gebeine. Funde: Tiillenaxt $=$ VAM 22, 9; 
Messer abg. VAM 26, 34; Meißel mit Horngriff abg. VAM 27, 44; Nadel = VAM 28,$61 ;$ Fibel $=$ VAM 29,72; acht kleine tutuli, von den älteren (Plate, Peckatel), dadurch unterschieden, daß sie unter der Platte eine kleine Schlußscheibe haben, sicher Gürtelsclimuck und Vorläufer der gewölbten Schmuckplatten der folgenden Periode (Abb. 16). Höhe 2, Dm. 1,2 cm.

Ihr Vorkommen in demselben Gra-

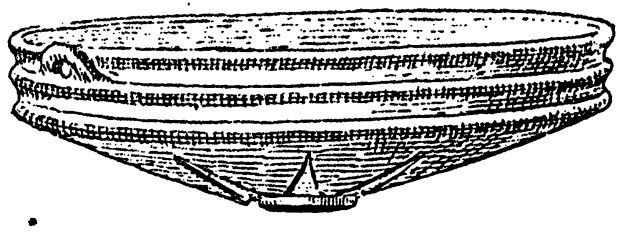

Abb. 15. $1 / 1$ be mit dem fraglichen Stück spricht doch dafür, daß dieses als Dose aufzufassen ist. Auch sollen sich in ihm Reste eines bräunlichen Harzes gefunden haben.

Auch dieses Grab, dessen Inhalt dem von Goldenbow sehr ähnelt, gehört sicher in die Schlußphase der dritten Periode. .

18. Weisdin bei Neustrelitz. Museum Neustrelitz.

Bruchstïcke. Boden zum Teil erhalten $16 \mathrm{~cm} \mathrm{D.} \mathrm{M.} \mathrm{Der} \mathrm{Boden} \mathrm{endet} \mathrm{in}$ einer Tutulus-ähnlichen Spitze, also ähnl. wie Montelius T. 91, aber die Spitze ist flach. Äußere Zone: Kleinere Lappen für Herzeinlage, mittlere. Zone etwas größere Lappen. - Deckel mit Verstärkungsrippen.

Gefunden 1863, dabei 11 "Hängetutuli besonderer Form; 19 Ringe mit kleinen frei schwebenden Stangen.

\section{Form C.}

M o n t e.li u s, Tidsbestämning 4, 92. S. M ü 11 e r, Ordning 355.

Eine bedeutende Formenänderung. Der Boden wird weiter vertieft und wird zu einem rundlichen Behälter von der Form eines flachen Kegels. Dieser ist nun das eigentliche Gefäß, die frühere Wand wird zum Halse, die Rippen verschwinden allmählich. Zwischen diesem Halse und dem Gefäßkörper schiebt sich ein Schulterstück ein. Dịe Henkel bleiben die alten, aber ein Deckel kommt nur noch ausnahmsweise und an typologisch frühen Stücken (z. B. Nr. 19, Parchim) vor. .

Auch die Ornamentik ändert ihren Charalster. Die gegossenen, vertieften Ornamente hören auf, an ihre. Stelle tritt die punzierte Linie. Die Lappen erscheịnen nicht mehr selbständig, sondern dienen zuir Bildung eines Sternmusters oder werden zu gezackten Kreislinienbändern verbunden. Besonders charakteristisch ist die Verzierung der Dose von Klueß (Nr. 21) : Die Lappen von der Basis losgelöst und zu in Spitzen aneinander schließenden Bögen gestaltet, die Vorstufe des herrschenden Motives der Folgezeit, des „laufenden Hundes“.

Die mecklenburgischen Stücke dieser Form sind nur klein; zwei zeigen ihren Charakter als Behälter zur Aufbewahrùng von Wertgegenständen besonders deutlich: in denen von Parchim und Suckow liegt Gold, Barren und Ringe, die zum Teil beschädigt sind und offenbar als Zahlungsmittel gedient haben; die Dosen stellen also Portemonnaies dar. Tutuli hat leider nur die Lose von Parchim, ihre Wölbung ist schon stärker als bei den oben abgebildeten und leitet zu den jungen glockenförmigen über; im einzelnen können wir aber die Entwicklung an unserem Material nicht verfolgen. 
Zeitlich steht die Dose von Parchim noch an der Grenze. von Periode III und IV (auch der Goldring trägt noch die Form der älteren Zeit), die anderen sind typisch IV.

19. Parchim.

Gestrichelte aufgehöhte Bänder am Rand und Halsansatz. Feines Saumornament aus gestrichelten Bändern und Linien. Falsche Spiralen mit gebogenen Verbindungslinien. Linie mit beiderseitigem Punktsaum. Auf der Schulter Winkelband aus Linienbündeln, Boden: Nur die Kreuzbalken vertieft (für Einlage), sonst punziert. Kleine Bögen. Großer Stern („Krückenkreuz") mit verbreiterten Armen und Punktsaum. Auf dem Mittelknopf konzentrische Kreise.

Höhe 5, Höhe des Halses 1,1, Breite der Schulter 1,3, Dm. oben 6, unten $8,4 \mathrm{~cm}$. Abb. 16 . Jahrb. 10 S. 281 (52 S. 9).

Gefunden 1844 in einer Steinkiste unter einem großen Stein (Jahrb. 10 S. 280), darin ein goldener Armring, ähnlich 'VAM 32, 89 (schmächtiger), 12 kleine tutuli aus Weißmetall, etwas von einander abweichend, meist $2,5 \mathrm{~cm}$ hoch $=$ VAM 41, 81; 11 flache runde Knöpfe mit Öse, abg. VAM 33, 106.

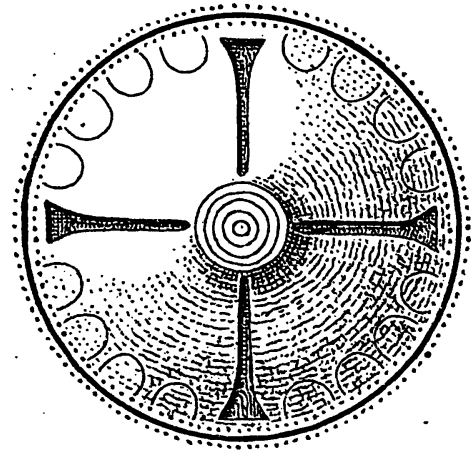

Abb. $16.1 / 2$.

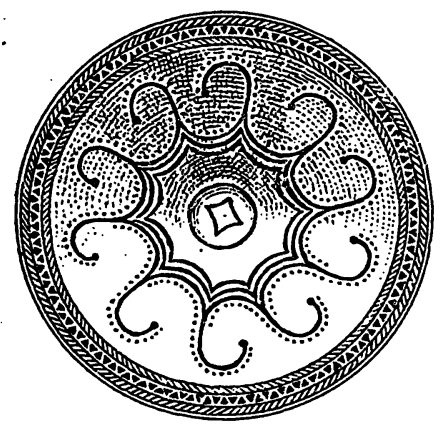

Abb. 17. $1 / 2$

20. Suckow bei Parchim.

Rand leicht ausgebogen, aufgehöhtes gestricheltes Band am Halsansatz. Boden: Verzierungen punziert (nicht für Einlagen). Saumornament aus Schrägstrichband, Kerbschnittband, zweifachem Punktband. Glatter Streifen. Streifen aus Punktlinie und Kerbschnittband. Halbbögen. Unverzierter Mittelknopf.

Höhe 5, Höhe des Halses 1,1, Breite der Schulter 1, Dm. oben 7,5, unten $9,4 \mathrm{~cm}$. Kein Deckel.

Gefunden 1852 an einem großenStein, zwischen einigen kleineren (Jahrb. 18 S. 204). Darin zwei goldene Handringe aus doppeltem Spiraldraht (= VAM 32, 90), der eine vollständig, der andere an den Enden abgebrochen und geknotet, ein kleiner gebogener Goldbarren mit unregelmäßig abgehauenen Enden; kleine Goldstange, offenbar der Rest eines Handringes.

\section{Klueß bei Güstrow 1 .}

Rand ausbiegend, Ösen leicht ausbiegend. Boden: Nur punzierte Ver zierungen (keine Einlagen mehr); Kerbschnittband zwischen gestrichelten Bändern. Die Lappen vom Grunde losgelöst, oben zu Haken umliegend, unten verbunden (dreistrichig); innerer Punktsaum. Auf dem Mittelknopf vierteiliger Stern. Kein Deckel.

Höhe 5,5, Höhe des Halses 1,6, Breite der Schulter 0,7, Dm. oben 7, unten (größte Weite) $8,9 \mathrm{~cm}$. Abb. 17 VAM S. 237, $2 \mathrm{~b}$.

Gefunden 1866 in einer Torfwiese im Forstbezirk Dewinkel (Jahrb. 32 a S. 7), dabei eine ähnliche Dose der Form D, ein Schwert abg. VAM 35, 3. 


\section{Form D.}

M o n t e li us, Tidsbestämning 4, 93. Ne e r g a a rd, J'af. XIX.

Der Ubergang ist unmerklich. Die Wandung rundet sich, so daß eine halbkugelige Form entsteht, sicherlich unter Einwirkung dor eingeführten Gefiiße des Hallstätter Kreises. Der Mittelknopf ist im Verschwinden. Die Gefäße werden größer („Hängebecken“), Deckel kommen nicht mehr vor. Der Hals hat keine Rippen mehr.

Das wesentliche Kennzeichen ist die Ornamentik. Die Lappen haben aufgehört, ihre Scheitel'werden zu Bogenreihen verbunden (s. Abb. 19), ihre Enden werden eingerollt (Schildbogenform), und so werden sie aneinander gelegt (s. Abb. 20); -die Harzfüllung wird selten und hört bald ganz auf. Das ist der echte Periode-IV-Stil. ${ }^{13}$ )

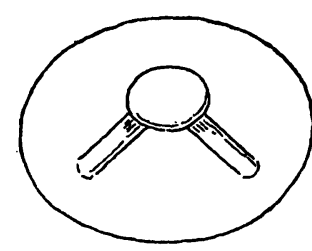

$\mathbf{a}$

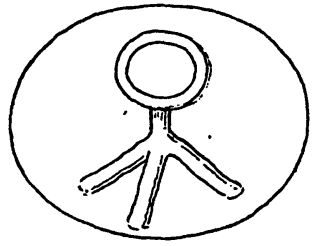

b

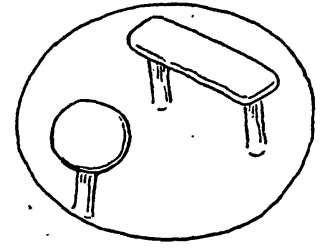

c

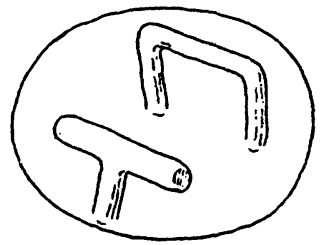

d

Abb. 18.

Die $T$ u $t$ u li dieser Stilrichtung entwickeln sich in der Richtung, daß sie wesentlich größer werden und dieOberfläche sich rundet. DieBefestigung geschieht zunächst noch wie bei dem Stück von Vorbeck (oben'17); dann aber tritt der Dorn ganz in das Innere und wird bei den großen Exemplaren mehrgliederig (s. Ạbb. 18). Für die UUbergangsform, beï der der Dorn im Innern befestigt ist, aber mit der Schlußscheibe herausragt ( $M$ o n t e li u s, Tidsbestämning 90. H a h n e, Vorzeitfunde aus Niedersachsen II, 3, aus dem sehr charakteristischen Funde von Klein-Hejsebeck) fehlen Beispiele in Mecklenburg. S. Monteliu s 90. S. Müller, Nord. Alt. S. J79, 198. $\mathrm{N}$ e e r g a a r d a. a. $\mathrm{O}$.

Mit der Form D beginnt eine néue Entwicklungsreihe. Die Becken werden größer, ihr Inhalt reicher. Ganz überwiegend sind es weibliche Schmucksachen (Hals-, Armringe und dergl.), die sie bergen, nur ausnahmsweise wie bei Brook ein Nutzgerät. Also dürfen wir auch diese Gruppe dem weiblichen Inventar zuschreiben. Schwieriger ist es zu bestimmen, ob auch der Gebrauch derselbe geblieben ist. Beobachtungen von Abnutzungsspuren sprechen dafür, daß auch. größere Becken am Gürtel getragen sind wie die kleinen Schmuckdosen der älteren Perioden. ${ }^{14}$ ) Dahin weisen auch die Schmuckkegel, die ja eine direkte Weiterbildung der älteren sind und daher auch demselben Zweck ge-

$\left.{ }^{13}\right)$ Für die Stilentwicklung besonders deutliche Stücke, auch durch den Hallstattvogel auf den Hängebecken s. S. M üll e r, Nordische Altertumskunde I; S. 379, $381 \mathrm{f}$. $\mathrm{N}$ e e r g a ard Taf. XIX.

14) $\mathrm{H}$ a h n e, a. a. O. S. 37. 
dient haben werden, und die regelmäßig mit den Becken, auch den größten, zusammen gefunden werden. Anderseits ist auffallend, daß Verschlußplatten, wie sie bei den früheren Regel sind, bei der Reibe Typ D bis F nicht vorkommen (soweit ich sehe, ist niemals eine dabei gefunden) und daß die Ösen eine andere Form annehmen, welche mit der alten Art des Verschlusses und der Befestigung nicht vereinbar ist. Auch ist es eine etwas harte Vorstellung, sich die umfangreichen schweren Gebilde wie das Brooker Becken mit massenhaftem Inhalt als am Körper getragen zu denken. Sie mögen allmählich mit ihrem Wachstum zu Behältern für Schmucksachen geworden sein, und die alte Benennung „Hängebecken“ dann zu Recht bestehen. Das Grabrituell kann in der jüngeren Bronzezeit einen Anhalt iiber die Art der Benutzung nicht mehr geben, es herrscht ja der Leichenbrand; auch sind die Becken durchweg Depotoder Votivfunde. In einem einzigen Falle ist eines in einem Grabe gefunden ${ }^{15}$ ); über einen anderen, wo der Fund im Zusammenhang mit einem Grabfunde zu stehen scheint, s. unten S. 115.

\section{Klueß bei Güstrow 2 .}

Der andern Dose von Klueß ähnlich, noch klein und altertümlich. Boden: Saum aus gekerbtem Band und kleinen Halbkreisen. An Stelle der Lappen stehende verbundene Halbkreise mit beiderseitigem Punktsaum. Sieben-

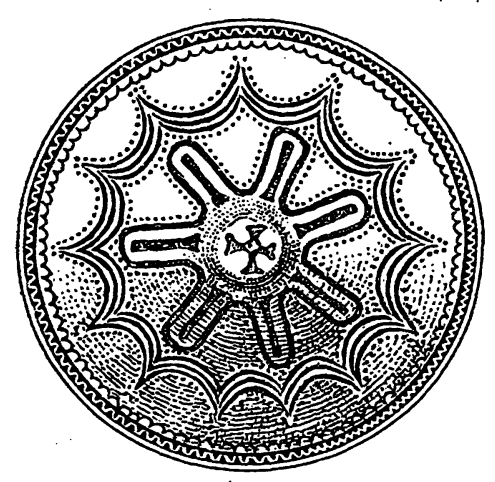

Abb. 19. $1 / 3$ teiliger'Stern aus Lappen mit Punktsaum; Umrisse und Mittelachse mit Einlage. Auf dem Mittelknopf vierteiliger Stern (für Einlage).

Höhe 6, Höhe des Halses 1,2, Breite 1, Schulter 1. Dm. oben 8,6 , unten $13 \mathrm{~cm}$. Abb. 19. VAM S. 237, 2a. Siehe oben S. 111 .

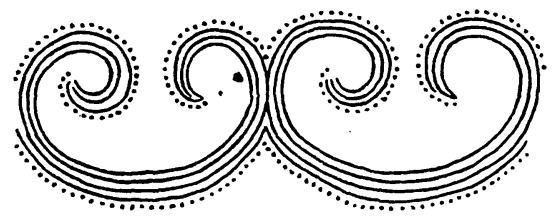

Abb. 20.

23. Lïbberstorf bei Warin 1 .

Der Boden zum Teil ausgebrochen. Aufgehöhtes Band am Halsansatz. Boden: Saum aus gestricheltem Bande, zwei Linien, Punktreihe. Die Lappen sind zu Schildbögen mit eingerollten Endigungen geworden (vierstrichig, mit äußerem Punktsaum). Mittelteil: dreistrichiges Band mit Punktsaum, Schildbögen.

Höhe 7,5, Höhe des Halses 1,2, Breite der Schulter 1,2, Dm. oben 11,5, unten $14 \mathrm{~cm}$. Abb. (des Schildornaments) 20. Jahrb. 52 Taf. I, 8.

Gefunden 1885 (Jahrb. 52 S. 6) 1/2 Meter tief im Boden. Beifunde: 1. Tutulus, ebd. Tafel I, 9; Knauf in leichter Wölbung abschließend. Zwischen Knauf und Kuppel zwei aufgehöhte Bänder. Zwei punzierte Bänder aus vier Linien mit beiderseitigem Punktsaum. Stuhl aus flacher Scheibe mit Schrägstützen. (Abb. 18a). 2. Zweites Becken, unten 25; 3. Tutulus dazu; 4. Handring VAM 40, 65, etwas einfacher ( $=\mathrm{S}$. Müller, Ordning 375, Neergaurd a. a. O.) von einer auf Periode IV beschränkten Form.

Höhe 6,5, Höhe des Knaufes 2, Dm. $7,8 \mathrm{~cm}$. Abb. Jahrb. 52, 'Taf. I, 9.

13) Insel Seeland; Mémoires 1916/17 9. 188.

Prähistorische Zeitschrift XIII. 1921. 
24. Ruthen bei Lübz.

Jin Bruchstück; ein stehender, ein fallender Bogen und Punktsaum. S. unten S. 120.

\section{Form $\mathrm{E}$.}

Montelius. Tidsbestämning 118, S. Müller, Ordning 389, Ne erga ard, Taf. XX.

Die Weiterbildung geht in der eingeschlagenen Stilrichtung weiter. Die Rundung wird noch stärker und gleichmäßiger, der Mittelknopf hört ganz auf. Die Gefäße werclen größer. Die Ornamentik ist nun eine voll entwickelte; das umlaufende stark bewegte Band herrscht durchaus. Wir konnten die Entwickelung aus den nebeneinander gestellten Lappen oben verfolgen, und alle Motive, außer dem Mäander, lassen sich zwanglos darauf zurïckführen, doch wird die Ähnlichkeit mit.Motiven, die in den klassischen Kultur]ändern Allgemeingültigkeit erlangt haben („laufender Hund", Triquetrum, Flechtband), so groß, daß eine Einwirkung oder Mitwirkung derselben zu der Formengebung im Norden nicht abzuweisen ist. Ein besonder's markanter Zug ist, wie die Spitzen der Wellen sich zu Drachenköpfen ummodeln, schwerlich spontan, sondern durch die Vogelprotomen und verwandte Erscheinungen, wie sie in der gleichstufigen ungarischen Bronzezeit so kräftig hervortreten, veranläßt. Wir gehen auf diese Verhältnisse nicht näher ein, da eine umfassende Behandlung von anderer Seite in Aussicht steht: Die Öse steht meist auf dem Rande wie bisher, greift aber anch oft in die Wandung ein. Es sind Charakterformen der fünften Periode.

Die T'utuli (Montelius, Tidsbestämning 116, 117; S. Müller, Ordning 396, N e e r g a a r d Taf. XXI, S p li e th 230) sind nun halbrund und glockenförmig geworden; sie wachsen wie die Becken, der obere Abschluß wird durch eine Scheibe mit Knauf auf einem zylindrischen Aufsatz gebildet. Die Befestigung wird konplizierter; sie wird zweigliedrig, meist ein dreiseitiger Bügel oder Stuhl, und ein in einer Scheibe oder Balken abschließender Stift (Abb. 18).

\section{Lübberstorf bei Warin 2.}

Öse in den Halsrand einschneidend. Band am Halsansatz. Boden: Vier Linien mit beiderseitigem Punktsaum; "laufender Hund" (dreistrichig) mit beiderseitigem Punktsaum; zweiter Saum glëich dem ersten; fünf "Laufende Hund"-Motive zu einem Muster vereinigt, aus dem ganz unorganisch eine Drachenprotome herausspringt. Vierliniger Mittelkreis (kein absetzender Knopf).

Höhe 10, Höhe des Halses 2, Breite der Schulter 1,2, Dm. oben 14,6, unten 17. $\mathrm{cm}$. Abb. a. a. O. Tafel I, 6.

Dazu ein Tutulus. Der Knauf abschließend in flacher Scheibe mit rundem glattem Aufsatz. Zwiei Bänder am Knaufansatz. Aufgehöhtes gestricheltes Band; "LaufenderHund" aus drei Linien mit äußerem Punktsaum. Stuhl aus zwei Gliedern: Balken auf Schrägstützen, Scheibe auf Stiel Abb. 18c.

Höhe 6,7, Höhe des Knaufes 2,5, Dm. 7,4 cm. Abb. a. a. O. Tafel I, 7. S. oben 23 . 
26. Brook bei Lübz 2.

Keine Öse, sondern vierseitige Ösenöffnung am Rande. Band am Rande und Halsansatz. Boden: Die punzierten Linien sind sehr dünn, wesentlich verschieden von denen bei Brook 1. Die äußere Kante mit Geradstrichbündeln; die die beiden äußeren Zonen teilenden Bänder sind aufgehöht und schräggestrichelt, das innere punziert mit kleinem Tannenwedelmuster. Zonen: Flechtband, Wellenband mit Drachenköpfen, Laufender Hund.

Höhe 9,5, Höhe des Halses 2,5, Breite der. Schulter 1,1, Dm. oben 16,25, unten $20 \mathrm{~cm}$. Abb. 21 (Das Ornament nicht richtig wiedergegeben). 22, Jahrb. 61 S. 223 , VAM 42,84 S. 237 , 2e. S. unten S. 122.

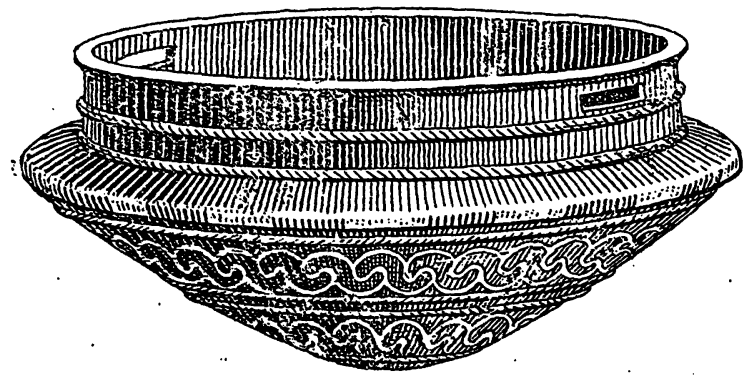

Abb. 21. $1 / 3$

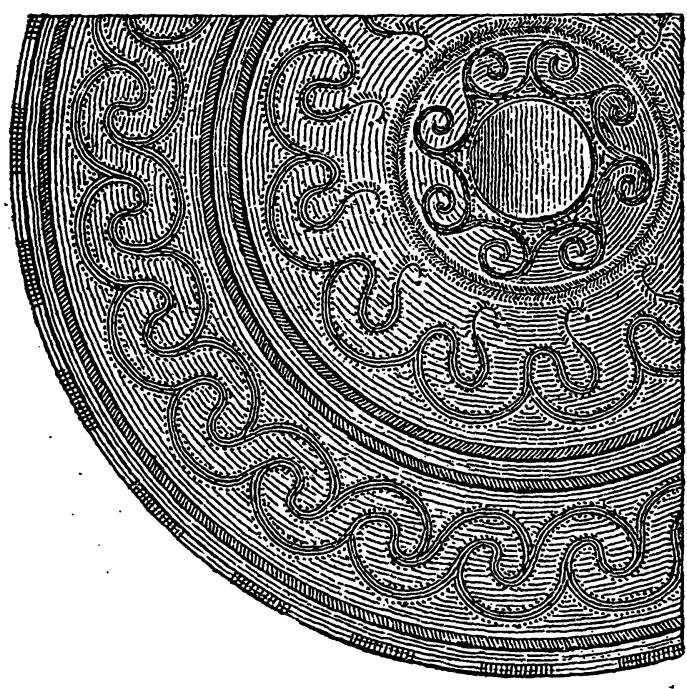

Abb. $22.1 / 2$

27. Goehlen bei Ludwigslust.

Flaue mäßige Arbeit. Das Band am Halsansatz fehlt. Punktreihe. "Laufender Hund“ aus vier Linien mit beiderseitigem Punktsaum. Um den unverzierten Bodenknopf zwei Reihen kleiner Halbmonde.

Höhe 6,6, Höhe des Halses 1,3, Breite der Schulter 1,1, Dm. oben 12,3, :unten 13,5 cm. Abb. 23/24.

Der Fund ist bisher nicht veröffentlicht.

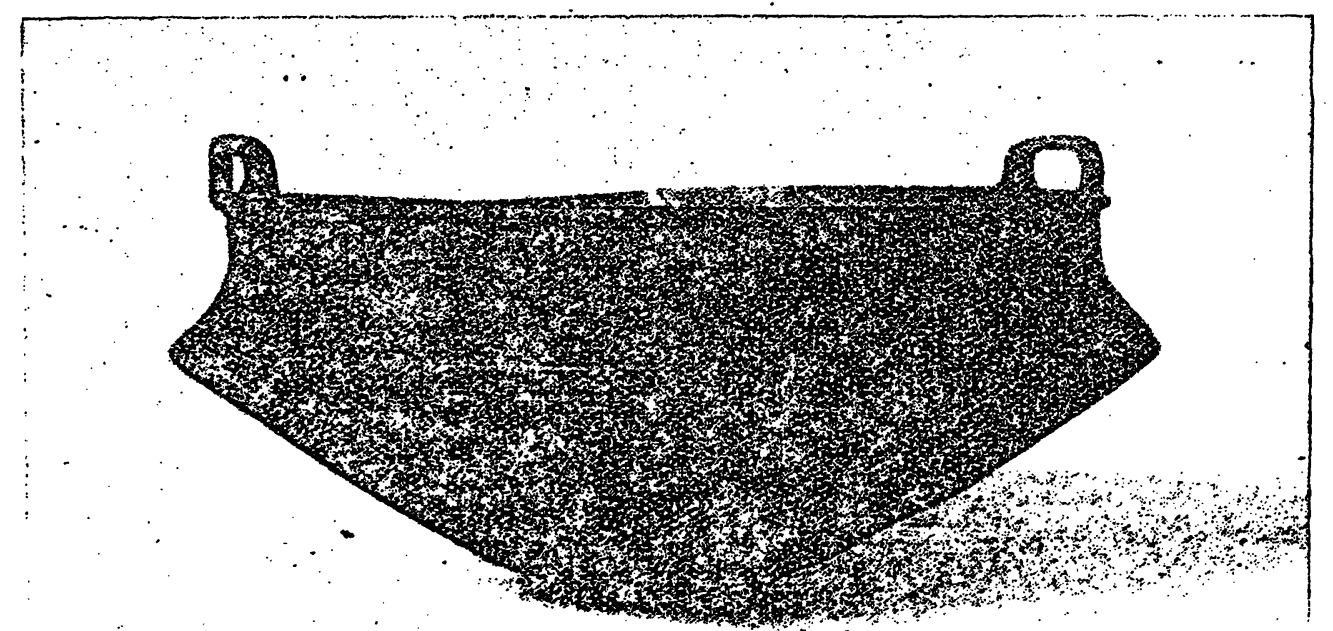

Abb. 23. $2 / 3$ 


\section{Depotfund und Urnenfeld von Goehlen bei Ludwigslust.}

Sïdwestlich von dem Dorfe Goehlen in der südlichen Heidesandebene, wclches bekannt ist durch die gute IBrhaltung seiner Dorfanlage als wendischer Rundling und die im Wendischen wurzelnde Eigenart seiner

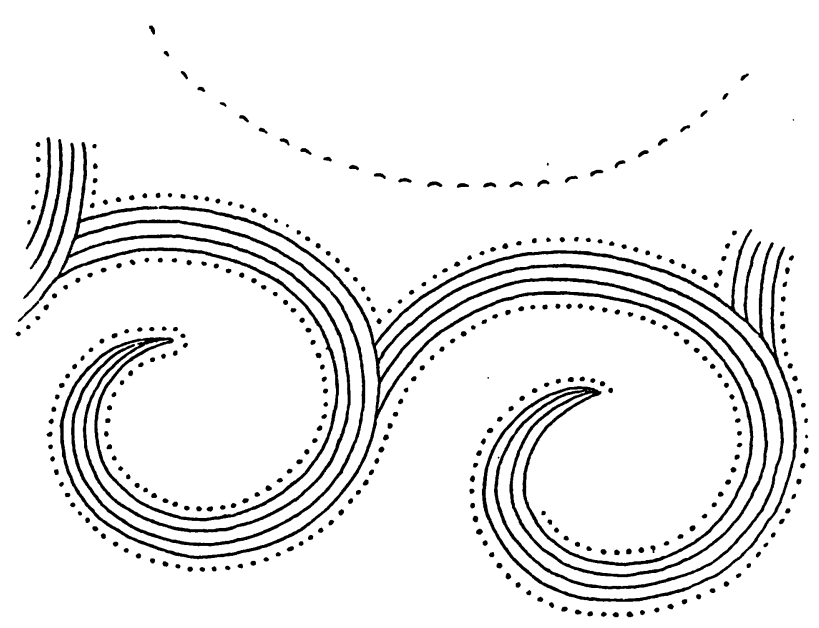

Abb. 24.

Bewohner, zieht sich ein kiesiger Höhenrücken, der Gusnitzberg, welcher im Sommer 1909 bei Gelegenheit einer Chausseeanlage abgebaut wurde. Dabei trat am Abhange des Berges ein Bronzefund zutage. Nach Bericht des Schachtmeisters Jahnke stand etwa $40 \mathrm{~cm}$ tief zwischen drei aufrecht gestellten Steinen und von zwei Steinen überdeckt ein "grüner Topf“" (das Hängebecken), in dem die übrigen Bronzen lagen.

Die Fundstïcke haben eine leichte, etwas körnige Patina, die von hellem zu dunklem Grün wechselt; es sind folgende:

1. Das Hängebecken (s. oben).

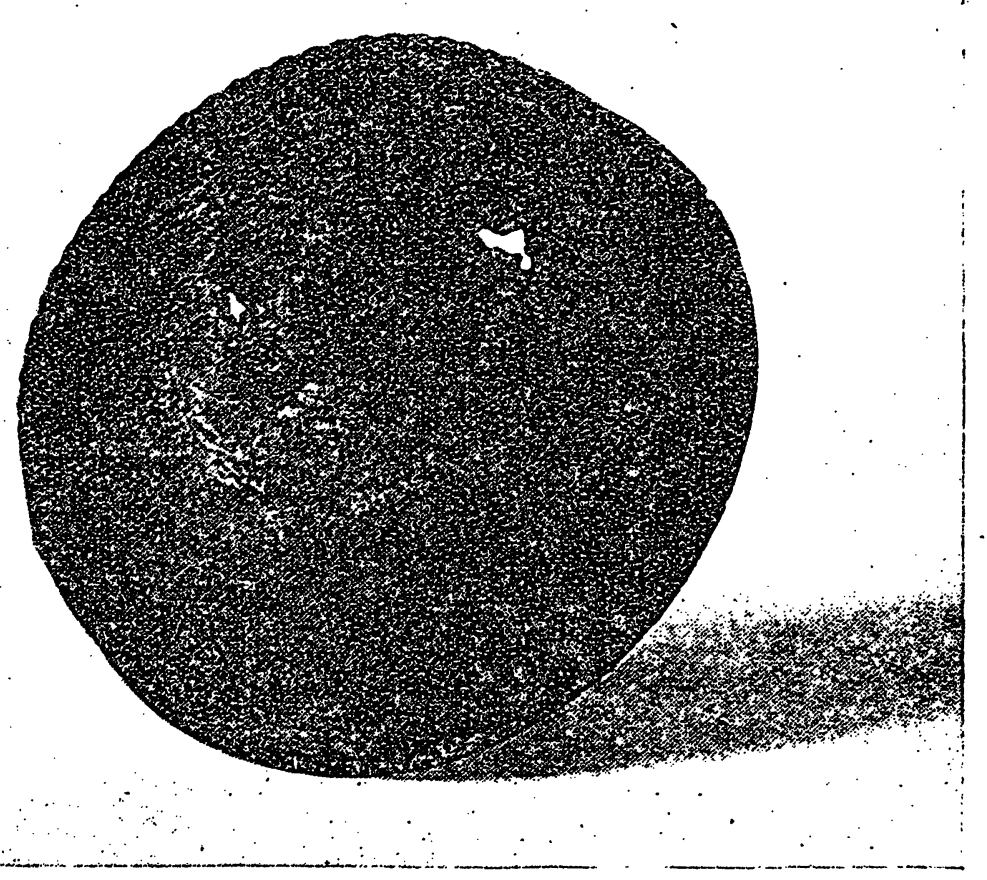

Abb. 25. $1 / 2$ 
2., 3. Zwei getriebene Schalen, ganz gleich. Rand leicht ausgebogen, Boden vertieft; am Rande zwei Löcher für einen Griff (keine Henkelöse, wie sonst an solchen Tassen). Zwei Reihen getriebener kleiner Buckel.

Höhe 5,7, Dm. $12 \mathrm{~cm}$. Abb. 25.

4., 5. Zwei getriebene Schmuckscheiben, ganz gleich. Innen angelötete rundliche Öse. Rand leicht erhöht, innen leicht gewölbte Fläche mit Buckel in der Mitte und Buckelreihe. Dm. $6 \mathrm{~cm}$. Abb. 26.

6 . Schmuckscheibe, den vorigen sonst gleich, aber ohne die Buckelreihe. Abb. 27.

7. Nierenring, gegossen. Das konkav-konvexe glatte Band schließt in zwei Erhöhungen, die durch ein Mittelstück mit stärkerer mittlerer Erhöhung und senkrechten Vertiefungen verbunden sind.

Höhe 0,9, Dm. 7,3 und 6,5 cm. Abb. 28.

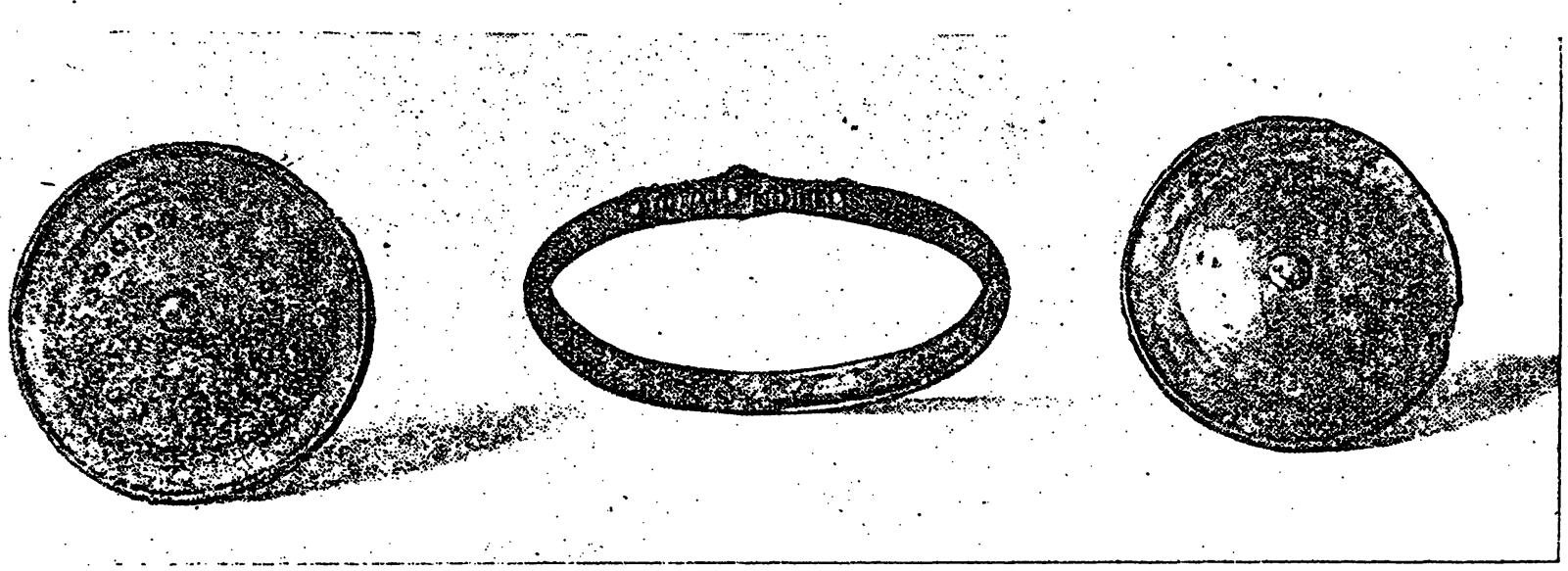

Abb. 26. $1 / 2$

Abb. 28. $1 / 2$

Abb. 27. 1/2

Das Hängebecken gehört in den oben besprochenen Formenkreis. Für die Schalen besitzen wir keine völligen Seitenstücke, sie sind wesentlich einfacher (auch die Buckel kleiner) als die sonst gleichen von Basedow, Dahmen, Kl.-Lukow, Lanken und Brook (VAM S. 254), die zum Teil noch einer etwas älteren Stufe (Periode IV) angehören mögen. Flache, halbkugelige Schalen wie die Goehlener, gehören einem jüngeren Hallstätter Kreise an ${ }^{16}$ ) (jetzt allgemein als 800-700 datiert), der im allgemeinen im Norden schon einer ersten Eisenzeit (Montelius VI) entspricht. ${ }^{17}$ ) - Die Schmuckscheiben haben hier ein Seitenstück in der ebenfalls getriebenen allerdings größeren Schmuckscheibe (Pferdeschmuck) aus dem Gießerfunde von Gr.-Dratow ; ${ }^{18}$ ) in den großen pommerschen Depotfunden kommen sie häufiger vor $;^{19}$ ) auch in der Altmark. Auch sie entstammen dem Hallstätter

16) Beispiele $\mathrm{N}$ a u e, Hügelgräber XXXVI, 4, Reinecke in Lindensch mit A. u. h. V., V., Nr. 1028, mit Bandhenkel, wie wir ihn ähnlich auch bei Goehlen voräszusetzen haben. Auch die Goldschale von Krottorf (Halle) kann als Parallele genannt werden. Schuch hardt, Goldfund von Eberswalde 1914, S. 25. Zum Henkel vergleiche auch das GoldgefäB. von Bihar (Ungarn) bei S c hu c h hardt, S. 22, Abb. 15.

15) Zur Herkunftsfrage s. K os sin n a, Maṇnus VIII S. 14 mit Beispielen ähnlicher Arbeit aus Nordost-Deutschland.

18) VAM S. 255, die anderen dort aufgeführten Scheiben sind gegossen.

19) Z. B. Koppenow; s. S chu man n, Bronzefund von Hoekendorf S. 2, s. auch K о в в in a a. a. O. S. 21; aus der Altmark $\mathrm{K} \mathrm{u} \mathrm{p} \mathrm{ka,} \mathrm{Stendaler} \mathrm{Beitrïge} 10$ S. 414 ; aus 
Kreise, aber einer älteren Stufe; einheimische Nacharbeit ist nicht ausgeschlossen; wie weit es sich im Einzelfalle um eine solche handelt, wird kaum zu entscheiden sein. - Der „Nierenring“ ist eine ostdeutsche Form, die aus der Schlu (bzeit der Bronzezeit in dio älteste Eisenzeit hineingeht. ${ }^{20}$ ) Unser Exemplar ist flacher und stïrker gegliedert als die sonst aus Mecklenburg bekannten. ${ }^{21}$ ) Mit ihm gewinnt das Verbreitungsgebiet eine weitere Ausdehnung nach Westen.

Eine Durchgrabung der Fundstelle durch Vfr. am 21. August 1909 ergab eine Anzahl Urnen, die erste etwa $10 \mathrm{~m}$ westlich von dem Bronzefunde. Die Urnen standen anscheinend in nordost-südwestlichen Reihen. 1, 2, 3 dicht zusammen ; 4, 5,6 in derselben Richtung nach SW, 80 bis $120 \mathrm{~cm}$ voneinander; eine zweite Reihe nördlich davon in ca. $1,50 \mathrm{~m}$ Entfernung enthielt die Urnen 7 und 8. Weiterhin war der Boden zerstört; aus vereinzelten Scherben ergibt sich, daß das Feld eine weitere Ausdehuung gehabt lrat. Sämtliche Urnen enthielten ziemlich große, von den Beimengungen des Brandes gesäuberte Gebeinreste, wie in dieser Periode üblich.

Es sind einfache naturbraune Gefäße.

Nr. 1. $30 \mathrm{~cm}$ tief (vom Rande gemessen), auf einem Steine. Zarte Gebeine. Doppelkonisch, Grundform VAM S. 258, 1. H. 14,3, Dm. oben 22, unten 10. größter Umfang (8 von unten) $81 \mathrm{~cm}$. Abb. 29. Zwischen den Gebeinen ein Feuersteinmesser, prismatisch, unscheinbar, die Seiten mit Gebrauchsscharten, $4,5 \mathrm{~cm}$ lang.

Nr. 2. Etwas tiefer als 1, unmittelbar daneben, mit Standstein, Seitensteinen, aber nur umstellt, nicht verpackt, und Deckstein. Zerdrückt, doppelkonisch, ähnlich Nr. 1, aber breiter und flacher.

Nr. 3. Hochstehend und daher zerdrückt. Rötlich; Form nicht bestimmbar.

Nr.4. Tiefer als die übrigen, ohne Stein-

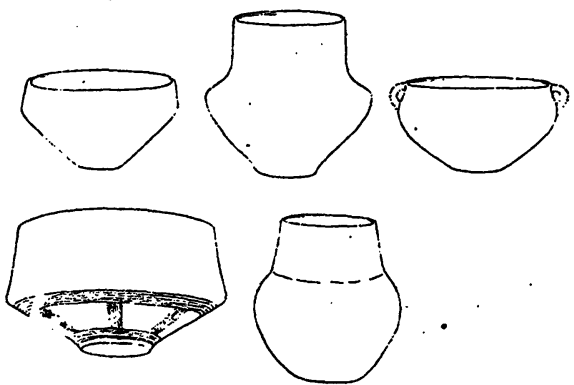

Abb. 29-33. schutz. Hoher Topf, Form VAM S. 259, 14 (aber ohne markierten Halsansatz).

Höhe 22,5, Dm. oben 17, unten 10,5, größter Umfang (10 von unten) $82 \mathrm{~cm}$. Abb. 30 .

Uberdeckt mit einer Schale, an der die Ansätze für zwei, jetzt fehlende, offenbar absichtlich abgebrochene Henkel.

Form ähnlich VAM S. 261,37. Wandung rauh. Hals leicht eingezogen.

Höhe 12,5, Dm. oben 22, unten $11 \mathrm{~cm}$. A.bb. 31.

In der Urne bronzener $\mathrm{P}$ f $\mathrm{ri}$ e m e $\mathrm{n}$; Kopf breitgehämmert, $4,5 \mathrm{~cm}$ lang.

Nr. 5. Hochstehend und zerdrückt. Flache breite Schale.

Darin bronzener Ring, an den Enden beschädigt; ganz einfach, innen gerade, außen konvex. Dm. 4,8 und $3,3 \mathrm{~cm}$.

Nr. 6. $40 \mathrm{~cm}$ tief; zwei Steine zur Seite. Zerdrückt. Derbe breite flache Schale.

- Nr.7. $40 \mathrm{~cm}$ tief; ohne Steinschutz. Doppelkonische Schale, Form VAM S. 258,1. Der untere Teil verziert; zwei unregelmäßige Strichzonen, 5 bis 6 Linien, verbunden durch senkrechte Streifen von meist 7 Linien. H. 19,5, Dm. oben 30,5, unten 11, größter Umfang (8,8 von unțen) $111 \mathrm{~cm}$. Abb. 32 .

Braunschweig Voges, Beiträge zur Anthropologie Braunschw. 1898 S. 80. Die kleinen sind sicher als Frauenschmuck anzusprechen.

2.) Kelege und Statistik von K o s s in n a, Mannus VIII, S. 2, IX, S. 186.

21) VAM S. 248 unten („Ringe mit Knotenwulst“); zu den dort aufgeführten kommt noch ein Stück (einzeln im Moor gefunden) von Bölkow bei Güstrow (Museum Güstrow). 
Nr. 8. Lage gleich der vorigen. Form VAM S.259,14, oben mit sehr schwacher Ausbuchtung. Höhe 23, Dm. oben 18, unten 11, größter Umfang (9,3 von unten) $78 \mathrm{~cm}$. Abb. 33 .

Bei der völligen Gleichheit der Lagerung in unmittelbarer Nachbarschaft ist die Zusammengehörigkeit des Depotfundes und der Grabfunde mit hoher Wahrscheinlichkeit anzunehmen. Das ist etwas ganz Nenes. Bekanntlich sind in der jüngeren Bronzezeit die oft außerordentlich reichen Depotfunde und die dürchgehend ärmlichen Grabfunde auch räumlich zwei getrennte Gruppen. Wenn hier beide zusammen vorkommen, so liegt darin eine Bekräftigung der alten Anschauung, daß die Depotfunde dem Verstorbenen gelten und einen Ersatz für die mangelude Grabausstattung darstellen sollen.

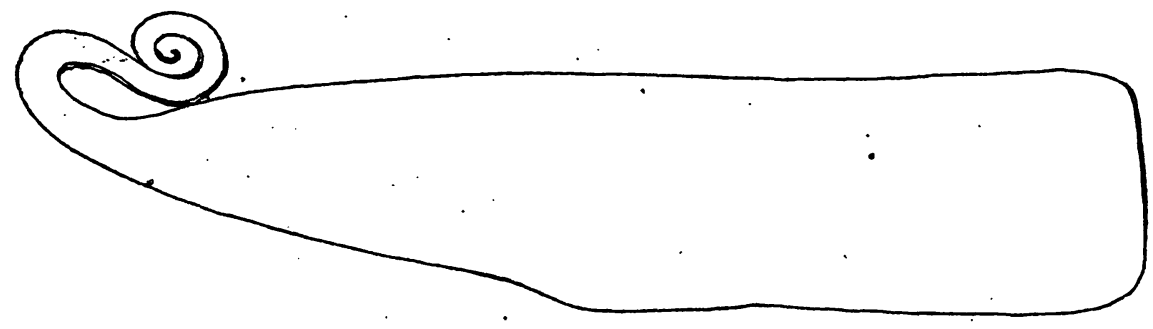

Abb. 34. $1 / 1$

In. der Sammlung befinden sich auch, ohne näheren Bericht, ältere Fundstücke von Goehlen, von denen einige mit den besprochenen vereinbar sind und ron derselben Stelle stammen könnten. Friderico-Franciscum S. 53 sind eine Anzahl Gegenstände (aus altem Bestande, vor 1804) aufgeführt, die sicher nicht zusammengehören. Einige sind typisch älterbronzezeitlich (Montelius II). Aber ein Messer (Abb. 34) 10,5 cm lang, ${ }^{22}$ ) ein einfacher Bronzering gleich dem oben besprochenen und eine Nảhnadel können wohl hierhingehören; 1829 ist beim Steinebrechen in einem Sandberge $70 \mathrm{~cm}$ tief eine Urne gefunden (nicht bewahrt), in der eine schöne Tüllenaxt lag; Form ähnlich VAM 37, 11; 9 cm lang. Jedenfalls ist die zeitliche Stellung dieser Funde dieselbe, die Schlußphase unserer Bronzezeit, Periode $V$.

28. Düssin bei Boizenburg.

Beschädigt, so daß die Ösenbildung nicht erkennbar ist. Sehr sorgsame Arbeit. Gestricheltes Dnppelband am Halse und Halsansatz. Boden: Saum aus drei aufgehöhten gestrichelten Bändern mit beiderseitigem Strichsaum. Gleiche Bänder $z w i s c h e n$ den Zonen. Die punzierten Linien tiefer als bei den bisherigen, aber nicht so tief wie bei Brook. Zone 1: Wellenband wie bei Brook. Zone 2: Mit einander verschlungene Schildbögen. Im Mittelkreise ,laufender Hund", linksläufig, an dem die Entstehung aus den Lappen noch deutlich ist. Der Mittelknopf umgeben von Strichband.

Höhe 11, Höhe des Halses 2,5, Breite der Schulter 1,3. Dm. oben un-. gefähr 20,5; unten $24,5 \mathrm{~cm}$.

Gefunden angeblich in einer Steinkiste, erworben 1872 (Jahrb. 37 S. 204). Abb. $35,36$.

29) In VAMI ist. die Form nicht abgebildet; sie bildet den Ubergang von VAM 38 , 24 (der vierten Periode) zu 38,23 (wohl erst der sechsten Periode angehörend). 
29. Ruthen bei Lübz.

Zwei Bruchstïcke (zu demselben Gefäße gehörend?). Erkennbar drei Bänder am Rande; "laufender Hund" ohne Punktsaum; doppeltes Band aus Linien mit Füllung von Senkrechten und Punktsaum.

Gofunden 1874 auf dem Grunde cines kleinen Torfmoors (Jahrb. 39 S. 127). Gegen 100 Stiicke Altmetall, Rohmetall und Gußzapfen (Gießerfund der Periode V). ${ }^{23}$ )
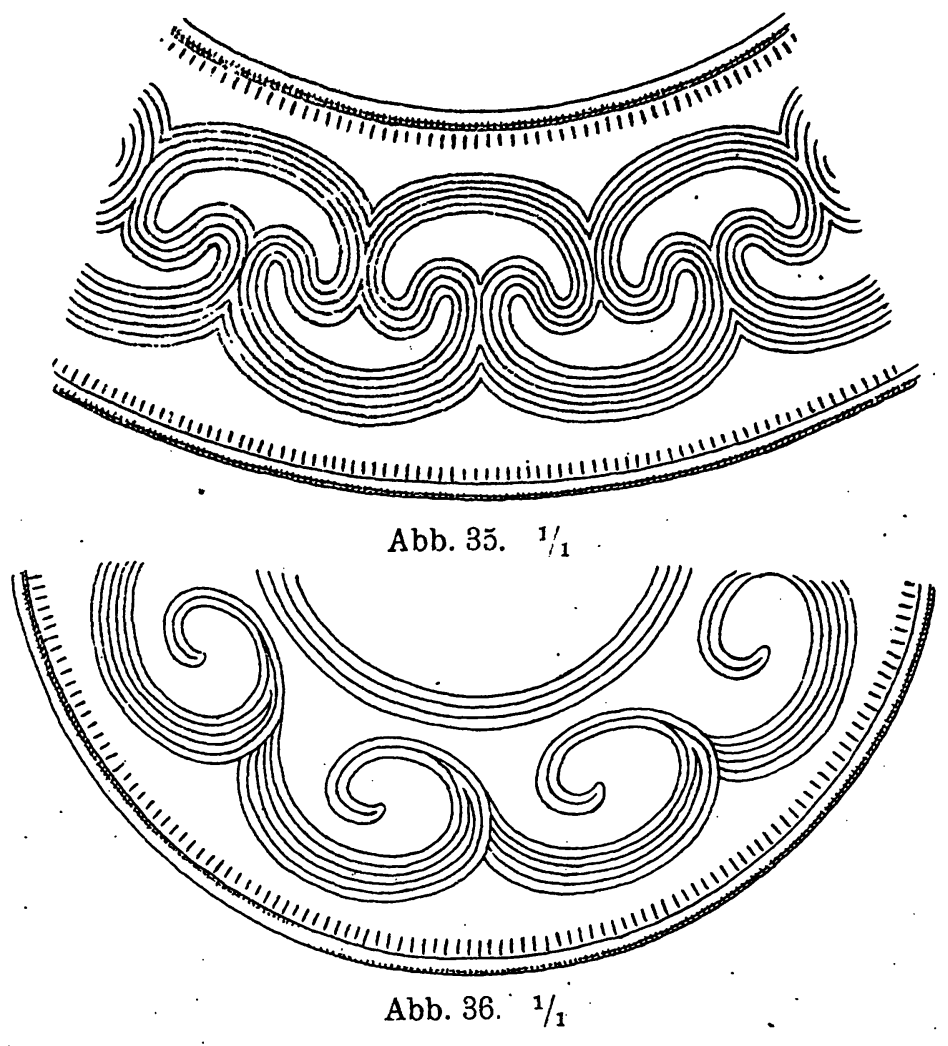

30. Basedow bei Malchin.

Öse in die Wandungen eingreifend. Alle Órnamente aufgehöht., Gestricheltes Doppelband am Rande, einfaches am Halsansatz; auf dem Halse Doppelband durch Halbkreis verbunden. Boden: Gestricheltes Doppelband, Punktreihe, gestricheltes Doppelband; konzentrische Kreise, vierteilig, zweite Punktreihe zwischen gestrichelten Doppelbändern, zweite Kreiszone, Mittelkreis aus drei Liinien. Mittelknopf aus vier Linien.

Höhe 10, Höhe des Halses 3, Breite der Schulter 1,8, Dm. oben 18,3, unten $23 \mathrm{~cm}$.

Privatbesitz. Abb. Jahrb. 14 S. 320, (61, S. 224), Lind e n schmit. A. u. h. V. II. IX. 1,3. Gefunden 1847 auf dem Felde unter Steinen, darin zwei halbkugelige Buckel (Pferdeschmuck), .etwa gleich VAM Taf. 43, 97), zwei gewundene Halsringe mit Hakenverschluß.

\section{Wendorf bei Penzlin.}

Nur der Boden erhalten, also. zweifelhaft, ob E oder F. Die Linien besonders zart. Zwei Zonen durch aufgehöhte Bänder getrennt, a) äußere: dreifache W.ellenlinie mit Punktsaum; 14 schildartige Verzierungen der Art VAM S. 287, 2c, aber die inneren Spitzen in Drachenköpfe auslaufend; b) 6 schildartige Verzierungen ohne Drachenköpfe: Dm. $22 \mathrm{~cm}$. Museum Neustrelitz. Gefunden 1860 in einer Wiese (Moorfund). Reiche Beigaben der fünften Periode. ${ }^{24}$ )

23, Aufzählung bei K os s i n n a, Mannus.VIII S. 74, doch ist dort zu streichen: 2 kleine Ösenknöpfe, 42 kleine Gürtelscheibenknöpfe, 6 Klapperblechsysteme, 1 Lappenbeil.

21) Aufzählung bei Kos s i n n a; Mannus VIII S. 83 . 
32. Wesenberg.

Gestricheltes Band an Hals und Halsansatz. Boden: Saumband aus drei Linien,-- die Zonen durch ein ähnliches getrennt. 1. Zone: Wellenband mit beiderseitigem Punktsaum; „laufender Hund“ mit beiderseitigem Punktsaum. Höhe 7, Höhe des Halses 1,75, Breite der Schulter 1,5, Dm. oben 16, unten $21,5 \mathrm{~cm}$. Museum Neustrelitz. . Abb. Baltische Studien XI, Taf. Fig. 3. Gefunden 1838 ",neben Steinen, Urnenscherben und Knochen“ auf der Pomel, einem Teile der Stadtfeldmark. (Jahrb. 7 B S. 361). Dabei sieben Armringe (=VAM 40, 65; vgl. Ruthen und Roga, 29 und 36).

33. Gegend von Neubrandenburg 1.

Nur zur Hälfte erhalten. Außerordentlich feine Arbeit. Hals leicht eingebogen. (Úbergang zu F.) Auf Hals und Halsansatz drei gestrichelte Bänder. Boden: Die Zonen durch vier äußerst feine Bänder aus kleinen Dreiecken bezw. Rhomben mit Haken- und Strichsaum getrennt. Zone 1: Band mit Schlangen, die Köpfe au'sgebildet mit Ohren und Zungen; Zone 2: Wellenband; Zone 3: Schlangenband, einfacher als bei 1; dazwischen Würfelaugen, (vgl. den Tutulus von Lübbersdorf, Abb. 41). . Auf dem Boden Kreis stehender Halbkreise aus vier Linien.

Museum Neustrelitz (ein Bruchstück in Schwerin). Baltische Studien XI. Taf., Fig. 6. Dazu ein Tutulus verwandter Art.

Die vier naus der Gegend von Neubrandenburg“ stammenden Stücke sind 1804 aus der Sammlung des berüchtigten Gideon Sp on holz ( $†$ 1807) erworben. Sie sollen innerhalb der letzten Jahrzehnte des 18. Jahrhunderts (nicht zusammen) gefunden worden sein. Daß sie aus der Nähe des Wohnortes des Sponholz, Neubrandenburg, stammen, ist wahrscheinlich.

\section{Form F.}

M o n teli us, Tidsbestämning 119, S. M üll e r, Ordning 388.

Den Höhepunkt der Formenreihe darstellend. Die Ausmessungen werden noch größer. Die Rundung ist jetzt eine völlige. . Neu tritt hinzu eine Verstärkung des Halsrandes durch einen horizontalen Streifen innerhalb der Öffnung, welcher mit Dreiecken oder Kreisen durchbrochen ist. Die Öse wird oft durch eine rechteckige Öffnung unterhalb des Halsrandes ersetzt.

Es sind - wie auch schon die der voraufgehenden Formen - technisch vollendete Stücke der nordischen Gießerkunst in verlorener Form mit Wachsmodell. Auf die Technik soll hier nicht weiter eingegangen werden, erwähnt sei nur, daß die kleinen Bronzeblättchen (Lamellen), die zum Auseinanderhalten der beiden Teile (Kern und Mantel) der Tonform dienten, die "Gußkernstützen" auf der Innenseite bei mehreren Stücken (Lübberstorf 2, Brook 1. 2, Lübbersdorf, Roga) noch deutlich erkennbar sind. ${ }^{25}$ )

Die Ornamentik ist jetzt die voll entwickelte der fünften Periode; sie überzieht die ganze Fläche gleichmäßig, die aufgehöhten Bänder hören auf. Die Motive bleiben die stark bewegten verschlungenen Wellen; dazu, sicher dem Hallstattkreise entnommen, der Mäander, aber in die Stilrichtung der Zeit lineingezogen, indem die Ecken gerundet sind; die Drachenmotive gehen weiter, oft werden die Wellen in Schlangenleiber

23) S. dazu Neergaard, a. a. O. S. 103, Hubert Schmidt, Pr. Z. 1915 S. 95, Ha h ne, Vorzeitfunde aus Niedersachsen S. 31. 
mit Drachenköpfen aufgelöst. Die Schmuckplatten (tutuli) folgen der sich verïndernden Stilrichtung, die größten und am meisten verzierten Stücke gchören hierher.

Mit Becken dieser Form schließt die Entwicklung in unserem Lande ab. Wine Verfallsform, die schon in den Ubergang der Bronzezeit zur Wiscn̨eit gehört (Montelius VI $=$ Hallstatt $C$ ) und auf die Montelius, I)ie ïlteren Kulturperioden I, 1903 S. 65 aufmerksam macht, ${ }^{26}$ ) kommt hier nicht mehr vor.

\section{Brook bei Lübz 1.}

Am Boden beschädigt. Ausgezeichnete Arbeit. Ornamente tief und kräftig. Der innere Halsstreifen (schmaler als bei den folgenden) in Kreisen durchbrochen. Die Öse am Halsrande, halb in diesen hineingreifend. (M o n teli u s, Tidš-. hestämning S. 76c.) Am Halse dreistrichiger Mäander mit gebogenen Kanten. getrennt durch senkrechte Strichbündel mit seitlichen Wellenlinien und kleinen IIalbbögen. Boden: Saum aus punktiertem Bande mit je drei Linien eingefa@t: drei gleiche trennen die Zonen: 1. 2. Wellenband; 3. "Laufender Hund". Im Mitlelkreise Wellenband, einige kleine Schlingen. „Laufender Hund“; Triquetrum.

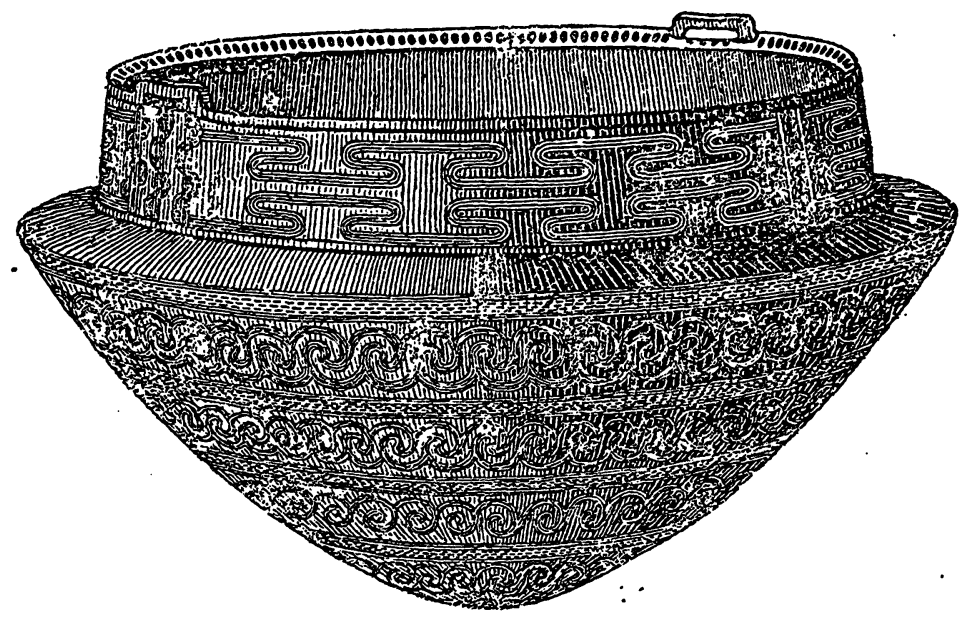

Abb. 37. $1 / 4$

Höhe 16, Höhe des Halses 4, Breite der Schulter 1, Dm. oben 21 (mit Halsstreifen 23,5), unten 28,1 cm. Abb. 37; 38, 39. Jahrb. 61 S. 221, 222. VAM 42, 85 S. 237, 2d. Gefunden 1890 in sandigem Boden. In diesem Gefäße lagen: 1. ein kleineres Hängegefäß, oben S. 115; 2. ein Tutulus, Knauf mit kleiner aufgehöhter Scheibe. Der. Knauf mit sechs aufgehöhten Bandlinien, dreifache Punktlinien am Knaufansatz. Verzierung sehr ähnlich der des Hängebeckens ron Basedow. Saum aus zwei aufgehöhten Bändern, eines gestrichelt, oben Reihe kleiner Striche; ähnlich der Abschluß von Zone 1 und 2. Zone 1: aufgehöhte konzentrische Kreise mit Mittelpunkt; Zone 2: aufgehöhte Punkte. Stuhl zweiteilig: rechteckiger Bügel, Starge auf Stiel. Abb.18d. Höhe 6,2, Höhe des Knaufes 1,7, Dm. 8,6 cm. Abb. 40. Jahrb. 62 S. 228, 26 (VAM 42, 83). Die Verzierung paßt zu keinem der beiden Hängebecken, entspricht aber der folgenden g etrieben en Trinkschale; 3. eine getriebene Schale aus Bronzeblech, sicher eingeführt, Abb. VAM 43, 94; 4. 5. zwei ungewöhnlich große Spiralarmbänder mit 39 Windungen; 6. gedrehter Halsring mit rerbreiterten Enden, auf denen eine Art Schiffsornament, Abb. Jahrb. 61 S. 230, VHM S. 237, 3; 7. 8. zwei gewundene Halsringe mit wechselnder Torsion,

${ }^{28}$ ) S. auch Kossinn a, Mannus VIII S. 122. 
der eine mit Ösen-, der andere mit Hakenverschluß; 9. Nadel einer gewölbten Plattenfibel; 10. Doppelknopf; 11. drei Stücke Bronzeblech, zu offenen Röhren zusammengebogen; 12. Tüllenaxt.

\section{Lübbersdorf bei Friedland.}

Drei aufgehöhte Bänder am Halse. Der innere Halsstreifen ist in Dreiecken durchbrochen, die Öse sitzt auf diesem Streifen, nicht am Rande; Boden: Die Zonen getrennt durch senkrecht gestrichelte Bänder, eingefaßt mit Punkt- und kleinen Halbkreislinien. Zonen: Wellenband; Schlinge mit Dirachenkopf; Wellenband, alle Ornamente vierstrichig und mit beiderseitigem Punktsaum. Auf dem Mittelknopf stehende Bögen.

Höhe 14,5, Höhe des Halses 4, Breite der. Schulter 1.7, Dm. oben 15 (mit Halsstreifen 19); unten $24 \mathrm{~cm}$.

Abb. Jahrb. 14 S. 325-327 (61 S. 226). Gefunden 1847, ungefähr 1,25 m tief in Moorerde in einer regelmäßig gebauten Kiste aus Sandsteinplatten. Beifunde: 1. Buckel; auf der Knaufplatte noch kleiner rundlicher vertiefter Aufsatz. Knauf mit 7 eingeschnittenen gestrichelten Bändern. Am Knaufansatz

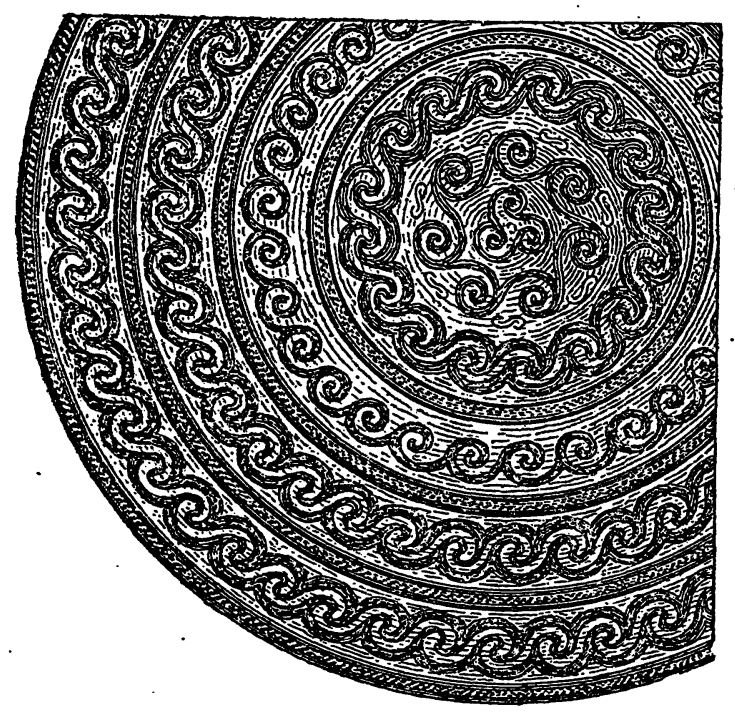

Abb. $38.1 / 2$

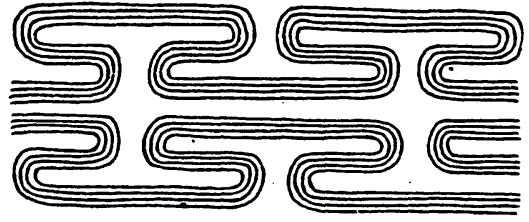

Abb. 39.

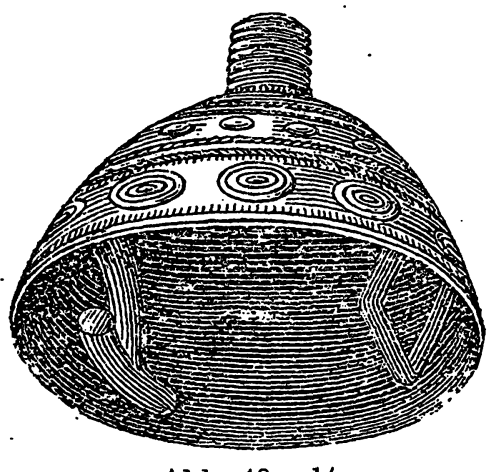

Abb. 40 . $1 / 2$

zwei aufgehöhte gestrichelte Bänder. Saum aus gestricheltem Bande. Die Zonen eingefaßt und getrennt durch aufgehöhte und eingeschnittene gestrichelte Bänder mit Strichsaum und Halbmondsaum. Zone 1: Wellenlinie; 2. "Laufender Hund". mit Drachenköpfen. In "den leeren Flächen Kreise mit Mittelpunkt. Stuhl einteilig: Scheibe auf drei Schrägstützen $=$ Abb. 18b. Abb.41.Jahrb. 14 S.328. Höhe 13, Höhe des Knaufs 3,5, Dm. 10,5 cm.; 2. Buckel. Knauf in leicht vertiefter Schale abschließend. Knauf mit fünf aufgehöhten gekerbten Bändern, eins am Ansatz. Saum aus zwei aufgehöhten gekerbten Bändern. Zone 1. Wellenband mit äußerem Punktsaum; Zone 2: Schlingen mit Drachenköpfen. Trennungsband aus Linienband mit. Füllung aus leicht gebogenen Linien, mit beiderseitigem Saum kleiner Halbmonde. Stuhl $=$ Abb. $18 \mathrm{c}$. Höhe 8,6, Höhe des Knaufs 2,8, Dm. $9 \mathrm{~cm}$. Jahrb. 14 S. 329; 3. Geschlossener Reif unbestimmter Verwendung („Diadem“), mit Einkèhlung, die eine Seite stärker hervortretend als die andere, Saumlinie, aufgehöhtes Band zwischen zwei Linien, Höhe 2,3, Dm. $19 \mathrm{~cm}$. (Abb. 42, a. a. O. 330): 4. Sechs "Nierenringe" (a. a. O. 331); 5. Kleiner Armring aus rundlichem Bande mit gerade abschneidenden Enden; verziert mit kleinen Senkrechten, zwischen denen leicht erhöhte Flächen, an der oberen und unteren Seite Band aus gebogenen Kerben, eine der nordischen Bronzezeit fremde Verzierungsart, in unserer 
Sammlung ohne Seitenstücke; das Stück wohl aus dem Hallstätter Kulturkreise eingeführl, wo die Form allgemein ist (im allgemeinen erst Stufe $C,{ }^{27}$ ) aber doch wohl auch schon in Stufe B, die unserer MV entspricht, vorkommend), Abl). 43. Dm. innen 5,2 und 4,5, Hühe $0,5 \mathrm{~cm} ; 6$. Z wei Armringe mit zylindrischen IVindungen, aus drejeckigem Diraht; 7. Sieben gewundene Halsringe mit Hakenverschluß, zwei davon mit Wechsel der Windung.

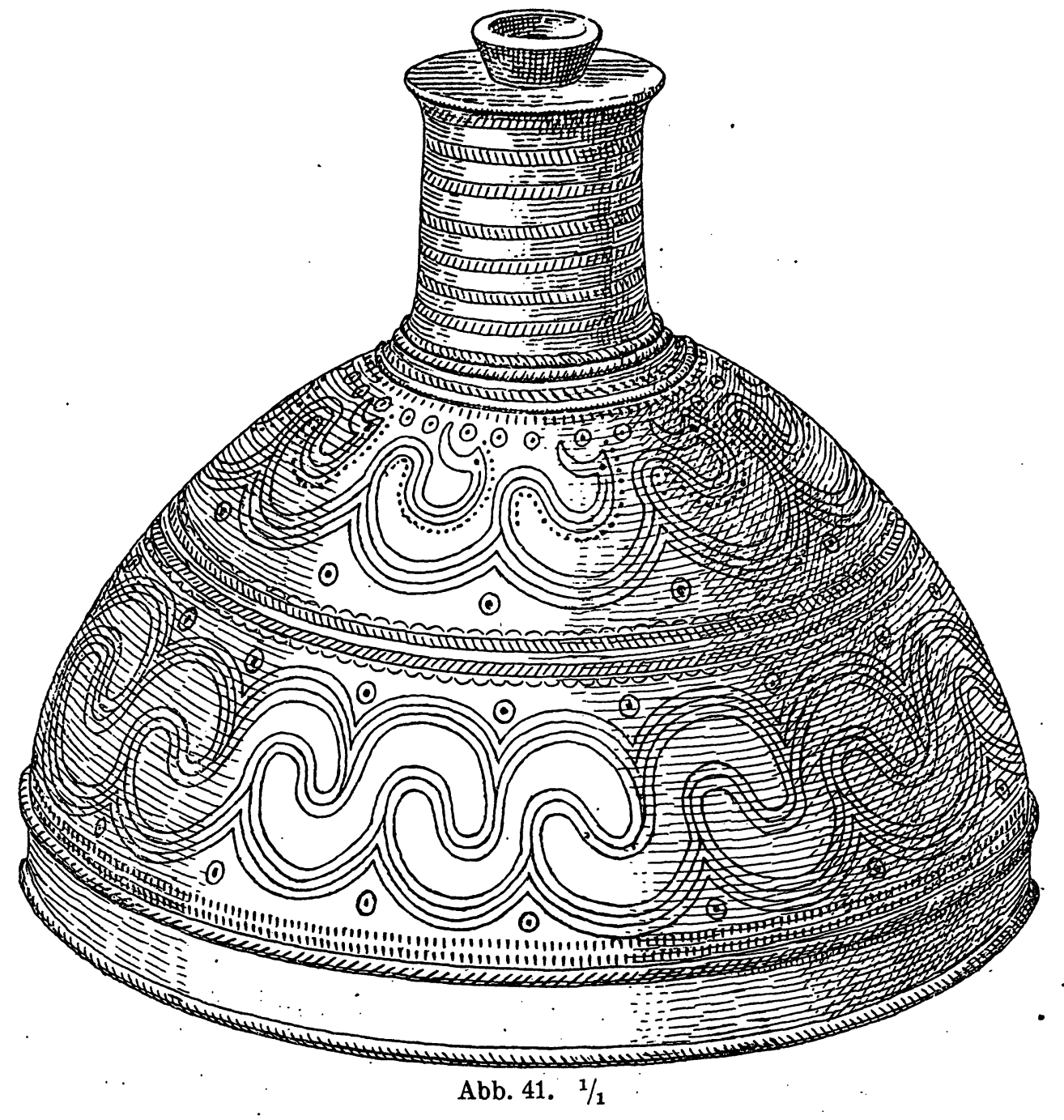

36. Roga bei Friedland.

Sehr ähnlich dem von Lübbersdorf. Im Halsstreifen sitzt in den Dreiecken zum Teil noch der Metallgrund. Drei Bänder am Halse. Boden: Zwei Zonen: Wellenband mit Punktsaum; im Mittelstück in einem Fünfpaß Schlingen mit Drachenkopf. Höhe 12,5, Höhe des Halses 3, Breite der Schulter 1,6, Dm. oben 14 (mit Halsstreifen 17), unten $22 \mathrm{~cm}$. Abb. Jahrb. 14 S. 327 (Jahrb. 61 S. .227) Abb. 44.

Gefunden 1840/41 in einem kleinen Teiche, etwa $1 \mathrm{~m}$ tief im Moder, das Becken umgestülpt, Armringe und Fußringe darunter, die uibrigen Sachen daneben. Beifunde: 1. Sechs Armringe =VAM 40, 65 (vg]. S. 113 bei Lübberstorf); 2. Bronzeband, wohl Gürtel, Abb. 45, mit eigentümlichen Verzierungen, darunter auch Drachenköpfe. Die Art, wie die Figuren ineinander verschlungen sind, weicht von dem Stil der nordischen Bronzen mit ihrer strengen Regelmäßigkeit so ab, daß wir in dem Stück ein eingeführtès sehen müssen; der

$\left.{ }^{27}\right)$ Z. B. N a u e, Hügelgräber, XXVI, 8. 


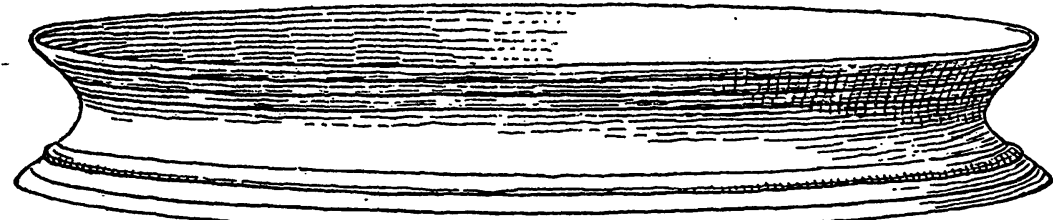

Abb. $42.1 / 1$

Kulturkreis, dem es angehört, würde als ein nachmykenischer mit Dipylonmotiven anzusprechen sein; 3. Spiralfingerring; 4. Zwei einfache Ringe; 5. Drei gewundene Halsringe mit Hakenverschluß; 6. Bernsteinspange (zugehörig?)

37. Gegend ron Neubrandenburg 2 .

Hals etwas nach innen gebogen. An Stelle der Ösen Öffnung unter dem Rande. Der innere Halsstreifen mit zwei Reihen kleiner Ringe. Gestricheltes Band auf dem Hals und Halsansatz, umgeben mit einer Reihe kleiner Haken. Boden: Saumband aus vier Linien, durch ein ähnliches, ebenfalls mit Haken gèsäumtes, Zone 1 und 2 getrennt; Zone 1 und 2 Wellenband; Zone 3 "Laufender Hund", die Spitzen in Drachenköpfe aufgelöst. Auf dem Bodenaufisatz ein vierstrichiges Triquetrum. Höhe 13, Höhe des Halses 1,5, Breite der Schulter 2, Dm. oben 13, unten $28 \mathrm{~cm}$. Museum Neustrelitz. Abb. Baltische Studien XI Tafel Fig. 4.

38. Gegend ron Neubrandenburg 3.

Unrollständig. Der in-

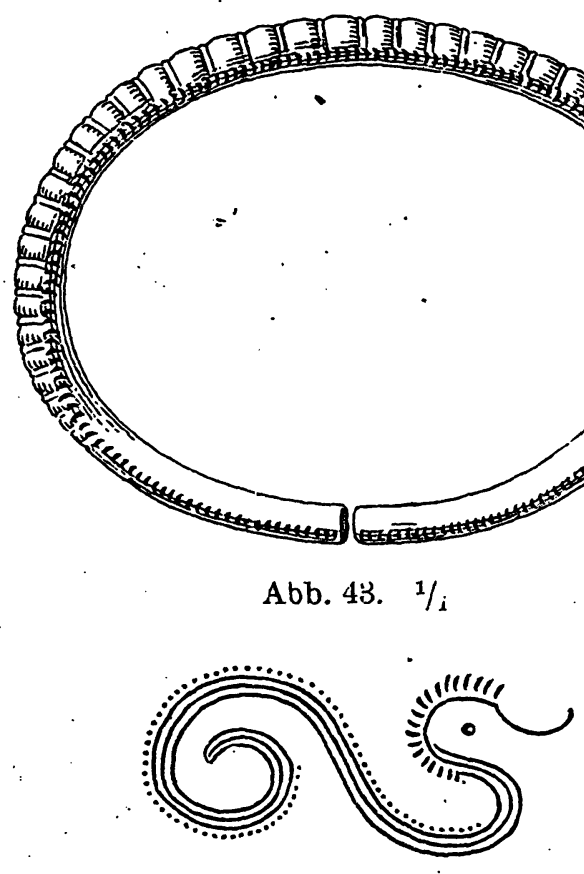

Abb. 44.

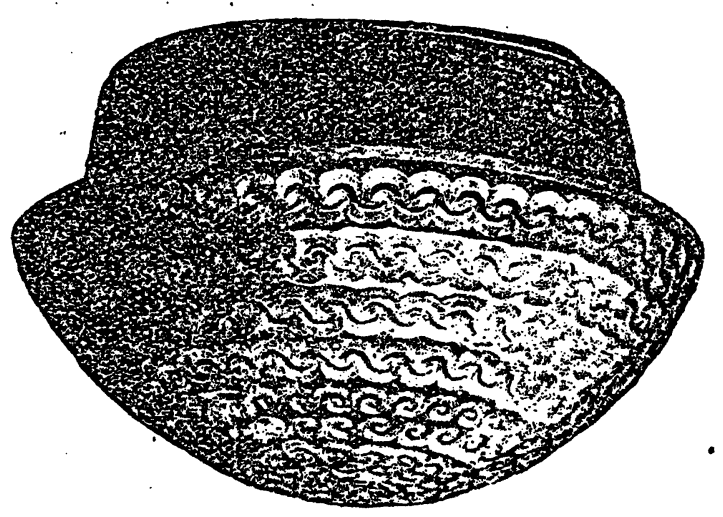

Abb. 46. $1 / 4$ nere Halsstreifen für durchbrochene Kreise angelegt, aber nicht fertig gearbeitet. Auf dem Boden vier kleine Halbbögen. Boden: Zone 1 von 2 durch Linienband mit Gradstrichen und beiderseitigem Punktsaum getrennt. 1. "Laufender Hund" in Drachenköpfe endigend, äußerer Punktsaum. 2. "Laufender Hund" mit etwas eingebogenen Seiten

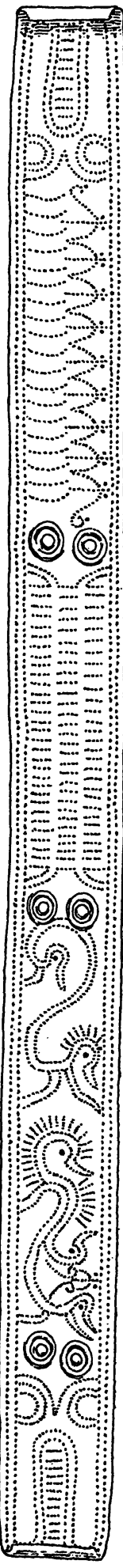

Abb. 45. (Ubergang zur Schlangenwindung). 3. "Laufender Hund" mit beiderseitigem Punktsaum. Höhe 10, Höhe des Halses 2,5, Breite der Schulter 1,75. Dm. oben 16, unten $22,5 \mathrm{~cm}$. Museum Neustrelitz. Baltische Studien XI (nicht abgebildet). 
39. Gegend von Neubrandenburg 4.

Dass größte der Strelitzer Gefäße, am stärksten gerundet. Der innere Halsrand mit Löchern mit erhabenen Rändern. Kein stehender Henkel, Öffnung am Halse. Am Halse drei Reihen Mäander mit gebogenen Ecken.

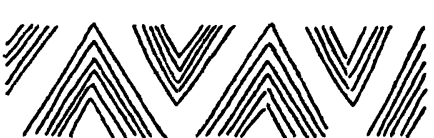

$1 a$.
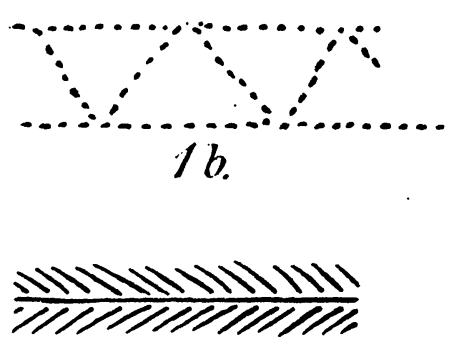

4 .

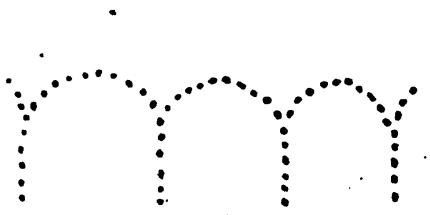

$7 a$.
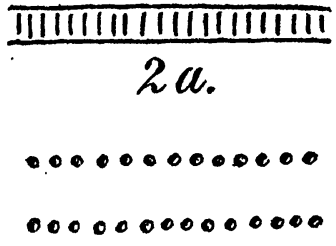

$2 b$.

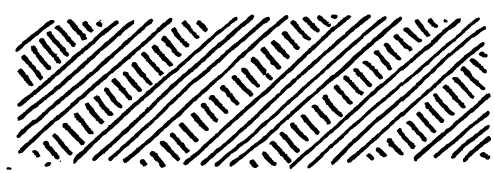

$3 a$.

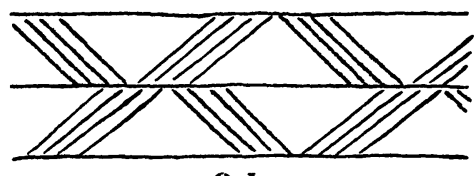

$3 b$.

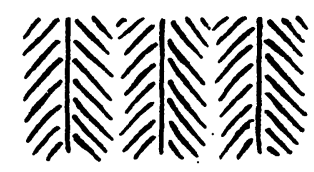

5.

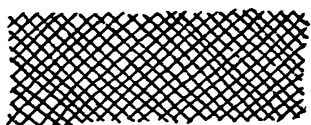

6 .
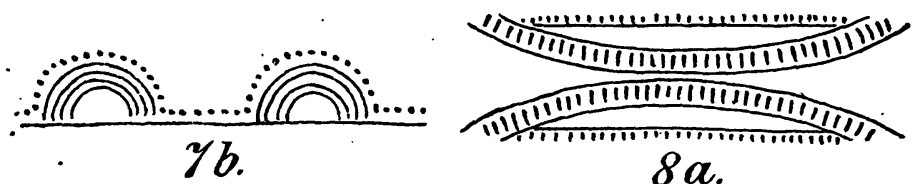

$8 a$.
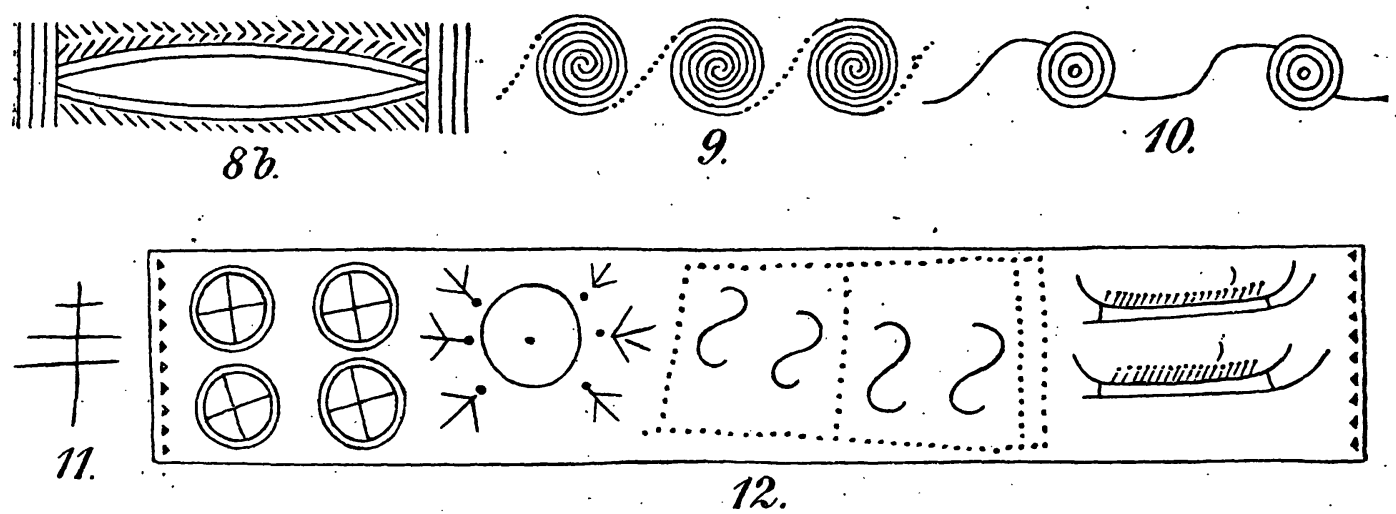

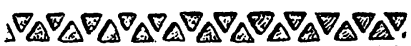

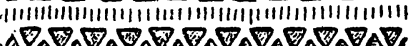
O 13.
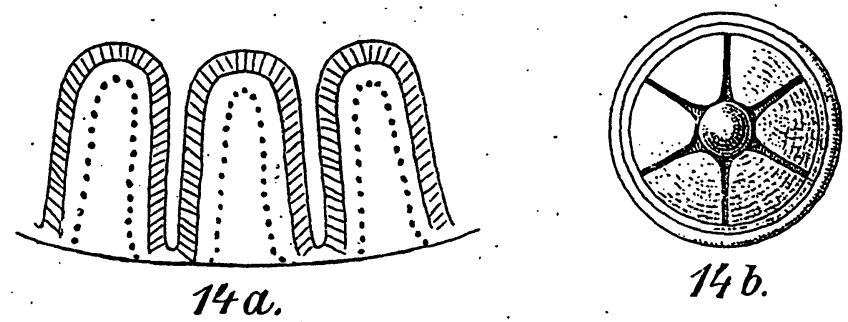

(Nr. $10 \mathrm{zu}$ oben Nr. 19.)

An der Schulter zwei geperlte Bänder. Boden: Die ganze Wandfläche mit Bändern überzogen, ohne Trennungsglieder. Vier Z Zonen Wellenband, vier Zonen "laufender Hund", in der Stellung und der Richtung abwechselnd. "Standfläche „laufender Hund“. Höhe 18,5, Höhe des Halses 5,75, Breite der Schulter 2, Dm. oben 16, unten $23 \mathrm{~cm}$. Museum Neustrelitz. Abb. 46. Baltische „Studien XI Taf. Fig. 5. 
$\mathrm{Zu}$ den Neubrandenburger Becken gehören zwei Tutuli. 1. Breiter Aufsatz mit kleiner Kopfscheibe. Befestigung $=$ Abb. 18b. Am Ansatz drei aufgehöhte gestrichelte Bandlinien. Zwei Linien mit Strichsaum. "Laufender Hund" mit heiderseitigem Punktsaum. Höhe 7,5, Höhe des Aufsatzes 2,5, Dm. 9,7 cm. Baltische Studien XI Taf. Abb. 11. 2. Breiter Aufsatz mit kleiner Kopfscheibe. Am Ansatz vier aufgehöhte gestrichelte Bandlinien. Befestigung $=\mathrm{Abb}$. 18b. Zwei Zonen getrennt durch Linienbänder, die zum Teil gestrichelt sind (mit Punktsaum). Obere Zone: Bandschlingen mit Drachenkopf. Untere Zone: "Laufender Hund" mit Drachenkopf. Höhe 11, Höhe des Aufsatzes. 3,5, Dm. $12,5 \mathrm{~cm}$. Baltische Studien XI Taf., Fig. 12.

\section{Die oberschlesischen Funde aus der römischen Kaiserzeit}

Fortsetzung und Schluß der Arbeit im Bande X dieser Zeitschrift,. S. 80 ff. Von Martin Jahn

(Mit 4. Tafeln)

Im ersten Teil dieser Arbeit habe ich die Hauptmasse des Fundstoffes, die Grabfunde bęhandelt. . Es schließen sich hier die seltener beobachteten Siedelungs- und Einzelfunde an. Einige Nachträge und Verbesserungen von Angaben im ersten Teil füge ich am Schlusse der Fundberichte bei. Fïr die Abbildungen auch dieses Abschnittes gilt das im Bande X S. 80 Gesagte. Eine Erläuterung der Abkürzungen befindet sich ebendort S. 81 . Den Fundbeschreibungen folgt ein allgemeiner Teil, in dem ich die Bedeutung des gesamten vorgelegteu Fundstoffes für die älteste Geschichte der germanischen Besiedlung Oberschlesiens darzulegen versuche.

\section{Scharley, Kr. Beuthen.}

Literatur: Schlesiens Vorzeit N.F.IV S. 193.

Auf dem Gelände der Cäcilie-Wäsche (Schlesische Aktiengesellschaft für Bergbau und Zinkhüttenbetrieb) östlich von Scharley stiess man im Jahre 1905 bei Schachtarbeiten auf vorgeschichtliche Wolnstätten. Dem umsichtigen Eingreifen des Herrn Berginspektors Gürich in Scharley ist es zu verdanken, dass der Inhalt von vier kaiserzeitlichen Siedelungsgruben sorgfältig. gehoben wurde. Herr Gürich schenkte den Hauptteil der Funde dem Breslauer Museum unter. genauer Angabe der Fundumstände. Im Jahre 1911 wurde bei Anlage neuer Klärteiche die vorgeschichtliche Siedelung wiederum angeschnitten und etwa zebn Gruben entweder völlig oder nur teilweise ausgenommen. Auch diese Funde übermittelte Herr Gürich zum grossen Teil dem Breslauer Museum; ein anderer Teil, den ich noch nicht kenne, gelangte ins Museum Beuthen.

Gruben 1 und 2: Nachdem die 20 bis $30 \mathrm{~cm}$ starke Mutterbodenschicht abgetragen worden war, zeichnete sich in dem kiesigen Sande eine dunklere Stelle ab. Bei weiterem Abschachten ergab es sich, dass es sich um zwei, durch eine etwa $2 \mathrm{~m}$ breite Sandbrücke getrennte, rundliche Gruben von $1 \mathrm{~m}$ Tiefe handelte. Ihre Durchmesser betrugen 2 und $3 \mathrm{~m}$. 